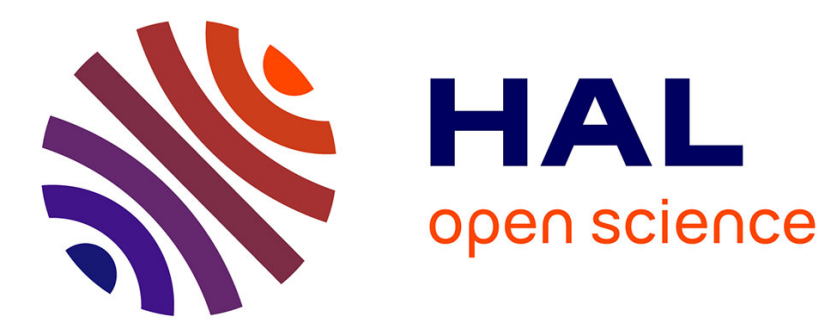

\title{
Mathematical modelling for solvated crystallization
}

\author{
Amira Rachah, Dominikus Noll, Fabienne Espitalier, Fabien Baillon
}

\section{To cite this version:}

Amira Rachah, Dominikus Noll, Fabienne Espitalier, Fabien Baillon. Mathematical modelling for solvated crystallization. IMA Journal of Applied Mathematics, 2017, 82 (1), p. 195-223. 10.1093/imamat/hxw012 . hal-01619248

\section{HAL Id: hal-01619248 \\ https://hal.science/hal-01619248}

Submitted on 17 Jan 2018

HAL is a multi-disciplinary open access archive for the deposit and dissemination of scientific research documents, whether they are published or not. The documents may come from teaching and research institutions in France or abroad, or from public or private research centers.
L'archive ouverte pluridisciplinaire HAL, est destinée au dépôt et à la diffusion de documents scientifiques de niveau recherche, publiés ou non, émanant des établissements d'enseignement et de recherche français ou étrangers, des laboratoires publics ou privés. 
IMA Journal of Applied Mathematics (2016) Page 1 of 28 doi:10.1093/imamat/xxx000

\title{
Mathematical modelling for solvated crystallization
}

\author{
A. RACHAH* \\ Institut de Mathématiques de Toulouse, Université Paul Sabatier, 118 route de Narbonne, \\ 31062 Toulouse, France \\ *Corresponding author: amira.rachah@math.univ-toulouse.fr \\ D. NOLL \\ Institut de Mathématiques de Toulouse, Université Paul Sabatier, 118 route de Narbonne, \\ 31062 Toulouse, France \\ dominikus.noll@math.univ-toulouse.fr \\ F. ESPITALIER AND F. BAILLON \\ Université de Toulouse, Mines d'Albi, UMR CNRS 5302, Centre RAPSODEE, Campus \\ Jarlard F-81013 Albi Cedex 09, France
}

[Received on 26 February 2016]

\begin{abstract}
We present a mathematical model for solvated crystallization of $\alpha$-lactose monohydrate based on population, mass and energy balance equations. We prove global existence and uniqueness of solutions under realistic conditions for a system operated in batch or semi-batch mode.
\end{abstract}

Keywords: modelling; existence and uniqueness; characteristic curves; crystallization.

2000 Math Subject Classification: 34B60, 35A01, 97M10

\section{Introduction}

Crystallization is the unitary operation of formation of solids from a liquid solution. In process engineering crystallization is an important separation technique used in the chemical, pharmaceutical, food, material and semiconductor industries (Mullin et al., 1971; Tavare, 1995). Crystallizers can be operated in batch, semi-batch or continuous mode (Jones, 2002).

The crystallization process is initiated if a solution becomes supersaturated. This may be triggered by cooling, evaporation of solvent, addition of anti-solvent, or by a chemical reaction. The principal processes in crystallization include nucleation or crystal birth, crystal growth, crystal breakage and attrition, agglomeration, but models should also include external processes like heating and cooling, or evaporation. Nucleation is the phase where solute molecules dispersed in the surrounding solvent start to form clusters, which according to the operating conditions are arranged in a defined periodic manner. Crystal growth is the subsequent accretion process of nuclei, driven by supersaturation. Crystal birth and growth cease when the solid-liquid system reaches equilibrium because of the exhaustion of supersaturation (Mersmann, 2001; Jones, 2002).

In the food processing industry there has been growing interest in the crystallization of lactose in (Mcleod, 2007; Mimouni, 2007; Mimouni A. et al., 2009). For a number of reasons, $\alpha$-lactose monohydrate is the most commonly used form of lactose in making medications. It is affordable, physically and chemically stable, easy to mix, it readily dissolves in but does not absorb water. Lactose monohydrate is available as a powder in different grades, density, and flowability. Here we present a mathematical 
model of solvated crystallization of $\alpha$-lactose monohydrate.

Two forms of lactose, $\alpha$ - and $\beta$-lactose, exist simultaneously in aqueous solution, the exchange being described by the process of mutarotation with exchange rates $k_{1}, k_{2}$. For temperatures $T \leqslant 90^{\circ} \mathrm{C}$ only $\alpha$-lactose crystallizes, with the specificity that a water molecule is integrated in the crystal. Nucleation and growth of crystals are the basic mechanisms, which may be complemented by modeling attrition, breakage, agglomeration and secondary nucleation effects.

Here we are interested in semi-batch crystallization, where the container is initially only partially filled. The model shown schematically in Figure 1 combines the dynamics of four interacting populations, one of them aging, governed by an energy balance. For a schematic view of the crystallizer, see Figure 2.

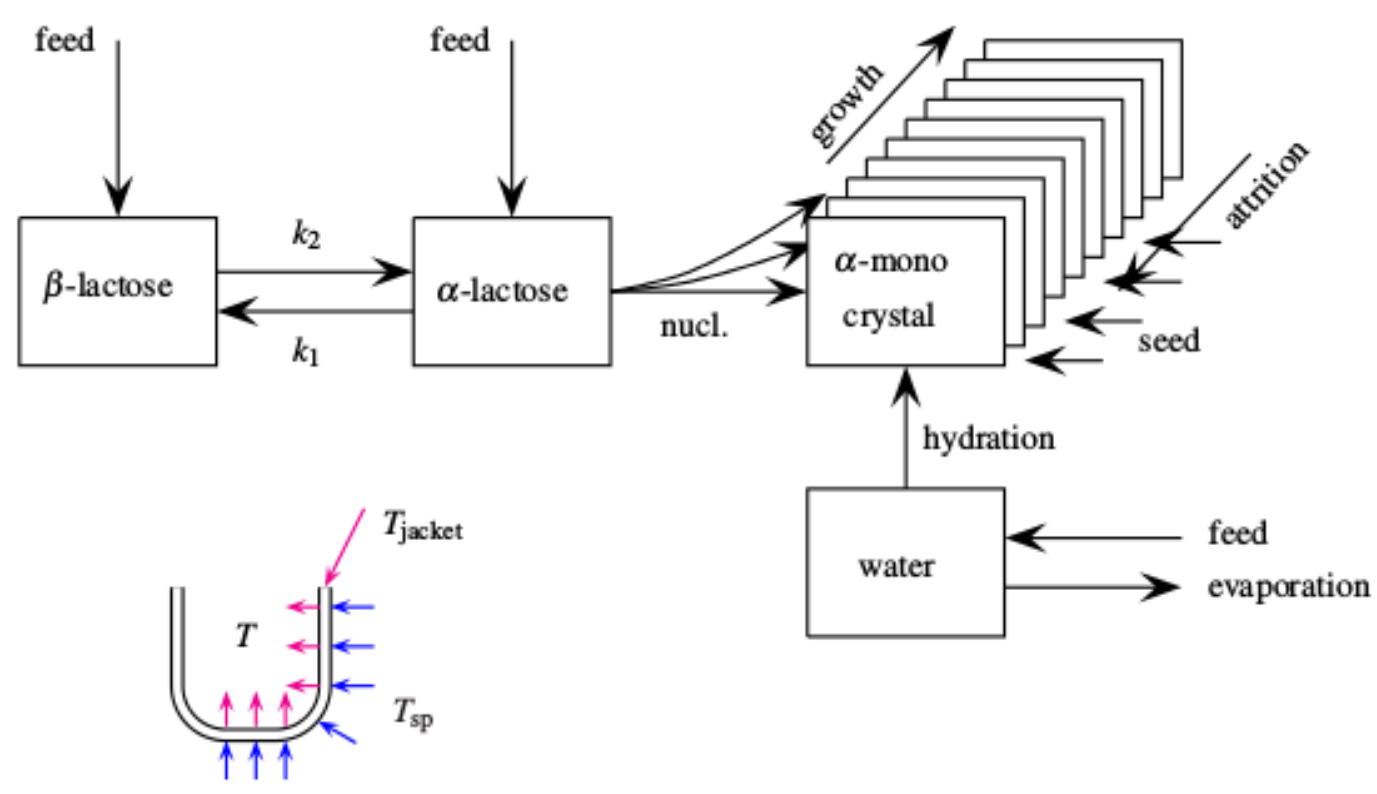

FIG. 1. Crystallization of $\alpha$-lactose monohydrate. The model includes four interacting populations: $\alpha$-lactose and $\beta$-lactose in liquid phase, water, and crystals of $\alpha$-lactose monohydrate. The two forms of lactose, $\alpha$-lactose and $\beta$-lactose, exist simultaneously in aqueous solution, the exchange being governed by mutarotation, with exchange rates $k_{1}$ and $k_{2}$, depending on the temperature, governed in turn by the energy balance. The latter includes the internal heat produced by the crystallization reaction, and the heating and cooling system used to trigger and control the process. Altogether this involves the temperature of the slurry (Mersmann, 2001), or suspension, $T(t)$, the temperature of the crystallizer jacket, $T_{\text {jacket }}(t)$ used in cooling the crystallizer, the set-point temperature $T_{\mathrm{sp}}(t)$ used to control the crystallizer jacket, and the temperature of the feed added during the process.

Mathematical models of crystallization are known for a variety of processes, but solvated crystallization of $\alpha$-lactose has not been discussed in the literature within a complete model including population, molar and energy balances. The model we derive here includes breakage and attrition, but does not include agglomeration, as the latter is negligible. We validate the model mathematically by proving global existence of solutions based on physically meaningful hypotheses. Our method of proof expands on Gurtin (see Gurtin et al. (1974)) and Calsina (see Calsina et al. (1995)), see also Smith (1994); Cushing (1989). 


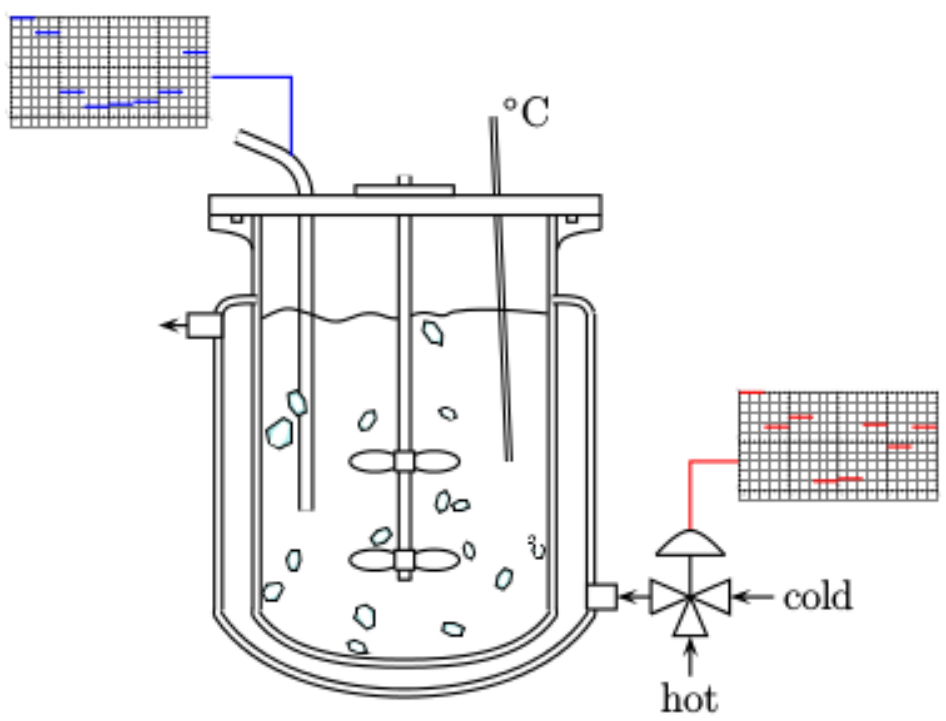

FIG. 2. Schematic view of the crystallizer, the container in which operated the crystallization process. Control inputs are the solute feed, and the set-point temperature.

For more general information on crystallization of lactose we mention Thurlby, Bronlund, Butler and Dincer (Thurlby et al., 1976; Bronlund, 1997; Butler, 1998; Dincer, 2000). In fact, lactose has long been regarded as a mere admixture, but recent research has revealed several new possibilities for its utilization (McSweeney et al., 2009).

The structure of the paper is as follows. In the section 2 we present the mathematical model of semi-batch solvated crystallization of $\alpha$-lactose monohydrate. In section 3 we present our main result on global existence and uniqueness of the solution. We conclude the proof of global existence and uniqueness by way of the characteristic curves and moments in discussed in section 4 . In section 3 we present realistic hypotheses which we need in the proof of our result. In section 5 we discuss prior estimates. Section 6 discuss the proof of our main result, which uses the method of characteristics with a fixed point argument for an operator, which acts as a contraction with respect to a specific metric. The final section 7 presents conclusions.

\section{Modelling and dynamics of process}

In this section we present the population, mass and energy balance equations which describe the dynamic model of crystallization of $\alpha$-lactose monohydrate.

\subsection{Population balance equation}

The population balance equation describes a first interaction between the population of solid crystals. characterized by their length $L$, and two ageless populations of solute molecules of the constituent in liquid phase. The population balance equation models birth, growth and death of crystals due to 
breakage and is given by

$$
\begin{aligned}
& \frac{\partial(V(t) n(L, t))}{\partial t}+G\left(c_{\alpha}(t), c_{\beta}(t), T(t)\right) \frac{\partial(V(t) n(L, t))}{\partial L} \\
& =-a(L) V(t) n(L, t)+V(t) \int_{L}^{\infty} a\left(L^{\prime}\right) b\left(L^{\prime}, L\right) n\left(L^{\prime}, t\right) d L^{\prime} \\
& V(0) n(L, 0)=V_{0} n_{0}(L) \\
& n(0, t)=\frac{B\left(c_{\alpha}(t), c_{\beta}(t), T(t)\right)}{G\left(c_{\alpha}(t), c_{\beta}(t), T(t)\right)}
\end{aligned}
$$

Here $n(L, t)$ is the distribution of $\alpha$-lactose crystals, CSD, that is, the number of $\alpha$-lactose crystals per unit volume $1 \mathrm{~m}^{3}$ and per unit length $1 \mathrm{~m}$, expressed as number $\cdot \mathrm{m}^{-3} \cdot \mathrm{m}^{-1}$. The quantities $c_{\alpha}(t), c_{\beta}(t)$ are the dimensionless concentrations of $\alpha$ - and $\beta$-lactose in the liquid phase, that is

$$
m_{\alpha}=c_{\alpha} m_{\mathrm{H}_{2} \mathrm{O}}, \quad m_{\beta}=c_{\beta} m_{\mathrm{H}_{2} \mathrm{O}},
$$

where $m_{\alpha}, m_{\beta}$ represent the mass of $\alpha$ - respectively $\beta$-lactose in the liquid phase, $m_{\mathrm{H}_{2} \mathrm{O}}$ the mass of water not integrated in crystals.

The total volume of slurry $V(t)$ in the crystallizer is a dependent variable given in (2.19), $G\left(c_{\alpha}, c_{\beta}, T\right)$ is the temperature-dependent growth coefficient of $\alpha$-crystals, or the velocity of crystal growth in $m \cdot s^{-1}$, assumed independent of crystal size $L$.

The boundary condition $n(0, t)$ involves the temperature dependent birth coefficient $B\left(c_{\alpha}, c_{\beta}, T\right)$, the velocity of nucleation or crystal birth in number $\cdot m^{-3} \cdot s^{-1}$. The initial condition $n(L, 0)$ represents the crystal seed $n_{0}(L)$.

The right hand side of (2.1) describes breakage and attrition. The breakage rate $a(L)$ represents the probability that a particle of size $L$ and volume $k_{v} L^{3}$ undergoes breakage, where $k_{v}$ is a volumic shape factor. The daughter distribution $b\left(L, L^{\prime}\right)$ represents the conditional probability that a particle of size $L$, when broken, produces a particle of size $L^{\prime}<L$. Following (Ziff, 1985), assuming that a particle breaks on average into $N_{p}$ parts leads to

$$
\int_{0}^{L} b\left(L, L^{\prime}\right) d L^{\prime}=N_{p}
$$

In the crystallization literature it is customary to assume binary breakage $N_{p}=2$, as this seems general enough to model practical phenomena. We refer to Ziff (Ziff, 1985), Kostoglou et al. (Kostoglou et al., 2002), Hounslow et al. (Hounslow et al., 2001), Ramkarishna (Ramkrishna et al., 2000) and Hede (Hede et al., 2006) for more information on fragmentation.

The sink term on the right of (2.1) gathers particles leaving size $L$ by being broken down to smaller sizes $L^{\prime}<L$,

$$
\mathscr{Q}_{\text {break }}^{-}(L, t)=\int_{0}^{L} a(L) b\left(L, L^{\prime}\right) n(L, t) d L^{\prime} .
$$

On the other hand the source term at size $L$ has the form

$$
\mathscr{Q}_{\text {break }}^{+}(L, t)=\int_{L}^{\infty} a\left(L^{\prime}\right) b\left(L^{\prime}, L\right) n\left(L^{\prime}, t\right) d L^{\prime},
$$

representing particles broken down from all possible larger sizes $L^{\prime} \geqslant L$ to size $L$. Now conservation of mass is ensured by

$$
\int_{0}^{L^{\prime}} L^{3} b\left(L^{\prime}, L\right) d L=L^{\prime 3}
$$




\begin{tabular}{||c|c|c||}
\hline \hline quantity & symbol & unit \\
\hline Crystal size distribution & $n(L, t)$ & number $\cdot m^{-3} \cdot m^{-1}$ \\
Crystal seed & $n_{0}(L)$ & number $\cdot m^{-3} \cdot m^{-1}$ \\
Crystal breakage rate & $a(L)$ & $1 / s$ \\
Breakage type & $b\left(L^{\prime}, L\right)$ & $1 / m$ \\
\hline \hline
\end{tabular}

Table 1. Size related quantities

Indeed, the total mass of crystals being broken is

$$
m_{\text {break }}^{-}(t)=\int_{0}^{\infty} a(L) n(L, t) L^{3} d L .
$$

On the other hand, the total mass of new crystals born due to breakage is

$$
\begin{aligned}
m_{\text {break }}^{+}(t) & =\int_{0}^{\infty} \int_{L}^{\infty} a\left(L^{\prime}\right) b\left(L^{\prime}, L\right) n\left(L^{\prime}, t\right) d L^{\prime} L^{3} d L \\
& =\int_{0}^{\infty} a\left(L^{\prime}\right) n\left(L^{\prime}, t\right) \int_{0}^{L^{\prime}} L^{3} b\left(L^{\prime}, L\right) d L d L^{\prime} \\
& =\int_{0}^{\infty} a\left(L^{\prime}\right) n\left(L^{\prime}, t\right) L^{\prime 3} d L^{\prime}=m_{\text {break }}^{-}(t),
\end{aligned}
$$

using (2.6). This confirms that breakage leaves the total crystal mass invariant. In contrast, if we compute the balance of number of individuals being broken, we obtain

$$
\begin{aligned}
\mathscr{Q}_{\text {break }}^{+}(t) & =\int_{0}^{\infty} \int_{L}^{\infty} a\left(L^{\prime}\right) b\left(L^{\prime}, L\right) n\left(L^{\prime}, t\right) d L^{\prime} d L \\
& =\int_{0}^{\infty} a\left(L^{\prime}\right) n\left(L^{\prime}, t\right) \int_{0}^{L^{\prime}} b\left(L^{\prime}, L\right) d L d L^{\prime} \\
& =\int_{0}^{\infty} a\left(L^{\prime}\right) n\left(L^{\prime}, t\right) N_{p} d L=N_{p} \mathscr{Q}_{\text {break }}^{-}(t),
\end{aligned}
$$

which confirms that breakage multiplies by $N_{p}$ the total number of individuals of that part of the population which undergoes breakage.

\subsection{Crystal mass and solvent mass balance}

We consider the mass $m_{\text {cry }}(t)$ of mono-hydrated $\alpha$-lactose crystals as a function of time and relate it to the crystal size distribution $n(L, t)$ through

$$
m_{\text {cry }}(t)=k_{v} \rho_{\text {cry }} \int_{0}^{\infty} V(t) n(L, t) L^{3} d L,
$$

where $\rho_{\text {cry }}$ is the crystal density. Therefore, we have

$$
\frac{d m_{\mathrm{cry}}(t)}{d t}=\rho_{\mathrm{cry}} k_{v} \int_{0}^{\infty} \frac{\partial(V(t) n(L, t))}{\partial t} L^{3} d L
$$


the initial condition associated with (2.7) being

$$
m_{\text {cry }, 0}=k_{v} \rho_{\text {cry }} V_{0} \int_{0}^{\infty} n_{0}(L) L^{3} d L
$$

The particularity of solvated crystallization is that the variations of solvent mass, $\frac{d m_{\mathrm{H}_{2} 0}}{d t}$, and of crystal mass, $\frac{d m_{\text {cry }}}{d t}$, are coupled. The fact that $\alpha$-lactose crystals integrate a water molecule means that molecular weights of the solid and liquid phase of $\alpha$-lactose are related as

$$
R=\frac{M_{\text {cry }}}{M_{\alpha}}=1.0525>1 \text {. }
$$

Therefore, if we temporarily define the mass of water inside crystals as $m_{\mathrm{H}_{2} 0 \subset \mathrm{cry}}$, we have

$$
m_{\mathrm{H}_{2} 0 \subset \mathrm{cry}}=\left(1-\frac{1}{R}\right) m_{\mathrm{cry}} .
$$

In consequence,

$$
\frac{d m_{\mathrm{H}_{2} \mathrm{O}}}{d t}=-\frac{d m_{\mathrm{H}_{2} \mathrm{O} \subset \mathrm{cry}}}{d t}+\dot{m}_{\mathrm{H}_{2} \mathrm{O}}^{ \pm}=-\left(1-\frac{1}{R}\right) \frac{d m_{\text {cry }}}{d t}+\dot{m}_{\mathrm{H}_{2} \mathrm{O}}^{ \pm}
$$

where $\dot{m}_{\mathrm{H}_{2} \mathrm{O}}^{ \pm}$includes external sources and sinks, like the feed of water during the semi-batch mode. The interpretation is that the variation of the free water mass $m_{\mathrm{H}_{2} \mathrm{O}}$ is governed by the inclusion of water molecules in crystals where it is bound, and by external sources and sinks.

By using the population balance equation (2.1), and by combining (2.10) and (2.7) allows us now to establish the solvent mass balance

$$
\frac{d m_{\mathrm{H}_{2} \mathrm{O}}(t)}{d t}=\left(R^{-1}-1\right) 3 k_{v} \rho_{\mathrm{cry}} G\left(c_{\alpha}(t), c_{\beta}(t), T(t)\right) V(t) \int_{0}^{\infty} n(L, t) L^{2} d L+\dot{m}_{\mathrm{H}_{2} \mathrm{O}}^{ \pm}(t) .
$$

\subsection{Mass balance of $\alpha$-lactose}

The next step concerns the mass balance for $\alpha$-lactose in the liquid phase. The variation of mass $m_{\alpha}$ of $\alpha$-lactose in the liquid phase is related to the variation of crystal mass $m_{\text {cry }}$ and the mass $m_{\beta}$ of $\beta$-lactose via

$$
\begin{aligned}
\frac{d m_{\alpha}(t)}{d t} & =-\frac{1}{R} \frac{d m_{\mathrm{cry}}(t)}{d t}-k_{1}(T(t)) m_{\alpha}(t)+k_{2}(T(t)) m_{\beta}(t)+\dot{m}_{\alpha}^{ \pm}(t) \\
& =-\frac{1}{R} \frac{d m_{\mathrm{cry}}(t)}{d t}+m_{\mathrm{H}_{2} \mathrm{O}}(t)\left[-k_{1}(T(t)) c_{\alpha}(t)+k_{2}(T(t)) c_{\beta}(t)\right]+\dot{m}_{\alpha}^{ \pm}(t)
\end{aligned}
$$

where $k_{1}$ and $k_{2}$ are the mutarotation exchange coefficients. Analytic expressions for $k_{1}$ and $k_{2}$ will be given in the section 2.7 .

The factor $1 / R$ in the first term takes (2.9) into account, while the second term models loss and gain of $\alpha$-lactose in the liquid phase due to mutarotation. The third term $\dot{m}_{\alpha}^{ \pm}$regroups external sources and sinks for $\alpha$-lactose. By definition of the concentrations we have $m_{\alpha}=c_{\alpha} m_{\mathrm{H}_{2} \mathrm{O}}$, so that

$$
\frac{d m_{\alpha}}{d t}=m_{\mathrm{H}_{2} \mathrm{O}} \frac{d c_{\alpha}}{d t}+c_{\alpha} \frac{d m_{\mathrm{H}_{2} \mathrm{O}}}{d t} .
$$


This leads to

$m_{\mathrm{H}_{2} \mathrm{O}}(t) \frac{d c_{\alpha}(t)}{d t}+c_{\alpha}(t) \frac{d m_{\mathrm{H}_{2} \mathrm{O}}(t)}{d t}=m_{\mathrm{H}_{2} \mathrm{O}}(t)\left[-k_{1}(T(t)) c_{\alpha}(t)+k_{2}(T(t)) c_{\beta}(t)\right]-\frac{1}{R} \frac{d m_{\mathrm{cry}}(t)}{d t}+\dot{m}_{\alpha}^{ \pm}(t)$.

Substituting (2.11) gives

$$
m_{\mathrm{H}_{2} \mathrm{O}} \frac{d c_{\alpha}}{d t}-c_{\alpha}\left(1-\frac{1}{R}\right) \frac{d m_{\mathrm{cry}}}{d t}=-\frac{1}{R} \frac{d m_{\mathrm{cry}}}{d t}+m_{\mathrm{H}_{2} \mathrm{O}}\left[-k_{1} c_{\alpha}+k_{2} c_{\beta}\right]+\dot{m}_{\alpha}^{ \pm}-c_{\alpha} \dot{m}_{\mathrm{H}_{2} \mathrm{O}}^{ \pm}
$$

which can be simplified to

$$
m_{\mathrm{H}_{2} \mathrm{O}} \frac{d c_{\alpha}}{d t}+\left[\frac{1}{R}-c_{\alpha}\left(1-\frac{1}{R}\right)\right] \frac{d m_{\mathrm{cry}}}{d t}=m_{\mathrm{H}_{2} \mathrm{O}}\left[-k_{1} c_{\alpha}+k_{2} c_{\beta}\right]+\dot{m}_{\alpha}^{ \pm}-c_{\alpha} \dot{m}_{\mathrm{H}_{2} \mathrm{O}}^{ \pm}
$$

We can interpret the source term $\dot{m}_{\alpha}^{ \pm}$as $\dot{m}_{\alpha}^{ \pm}=\dot{c}_{\alpha}^{ \pm} m_{\mathrm{H}_{2} \mathrm{O}}^{ \pm}+c_{\alpha}^{ \pm} \dot{m}_{\mathrm{H}_{2} \mathrm{O}}^{ \pm}$. Then we obtain

$$
m_{\mathrm{H}_{2} \mathrm{O}} \frac{d c_{\alpha}}{d t}+\left[\frac{1}{R}-c_{\alpha}\left(1-\frac{1}{R}\right)\right] \frac{d m_{\text {cry }}}{d t}=m_{\mathrm{H}_{2} \mathrm{O}}\left[-k_{1} c_{\alpha}+k_{2} c_{\beta}\right]+\dot{c}_{\alpha}^{ \pm} m_{\mathrm{H}_{2} \mathrm{O}}^{ \pm}+\left(c_{\alpha}^{ \pm}-c_{\alpha}\right) \dot{m}_{\mathrm{H}_{2} \mathrm{O}}^{ \pm}
$$

Dividing by $m_{\mathrm{H}_{2} \mathrm{O}}$ gives the equation

$$
\frac{d c_{\alpha}}{d t}=-\frac{1}{m_{\mathrm{H}_{2} \mathrm{O}}}\left[\frac{1}{R}-c_{\alpha}\left(1-\frac{1}{R}\right)\right] \frac{d m_{\mathrm{cry}}}{d t}-k_{1} c_{\alpha}+k_{2} c_{\beta}+\dot{c}_{\alpha}^{ \pm} \frac{m_{\mathrm{H}_{2} \mathrm{O}}^{ \pm}}{m_{\mathrm{H}_{2} \mathrm{O}}}+\left(c_{\alpha}^{ \pm}-c_{\alpha}\right) \frac{\dot{m}_{\mathrm{H}_{2} \mathrm{O}}^{ \pm}}{m_{\mathrm{H}_{2} \mathrm{O}}} .
$$

Our study uses $\dot{c}_{\alpha}^{ \pm}=0$ and $c_{\alpha}^{-}=0$, and $c_{\alpha}^{+}$constant, which means the fraction of $\alpha$-lactose in the feed does not change, even though the feed rate $\dot{m}_{\mathrm{H}_{2} \mathrm{O}}^{+}(t)$ is time-varying and may be used to control the process.

\subsection{Mass balance of $\beta$-lactose}

Proceeding in analogous fashion for the mass balance of $\beta$-lactose, we have

$$
\frac{d m_{\beta}}{d t}=k_{1} m_{\alpha}-k_{2} m_{\beta}+\dot{m}_{\beta}^{ \pm}
$$

which accounts for mutarotation and feed. Using $\frac{d m_{\beta}}{d t}=m_{\mathrm{H}_{2} \mathrm{O}} \frac{d c_{\beta}}{d t}+c_{\beta} \frac{d m_{\mathrm{H}_{2} \mathrm{O}}}{d t}$ in tandem with (2.11), we obtain

$$
m_{\mathrm{H}_{2} \mathrm{O}} \frac{d c_{\beta}}{d t}-c_{\beta}\left(1-\frac{1}{R}\right) \frac{d m_{\mathrm{cry}}}{d t}=m_{\mathrm{H}_{2} \mathrm{O}}\left[k_{1} c_{\alpha}-k_{2} c_{\beta}\right]+\dot{m}_{\beta}^{ \pm}-c_{\beta} \dot{m}_{\mathrm{H}_{2} \mathrm{O}}^{ \pm}
$$

Again we interpret $\dot{m}_{\beta}^{ \pm}$as $\dot{m}_{\beta}^{ \pm}=\dot{c}_{\beta}^{ \pm} m_{\mathrm{H}_{2} \mathrm{O}}^{ \pm}+c_{\beta}^{ \pm} \dot{m}_{\mathrm{H}_{2} \mathrm{O}}^{ \pm}$, then

$$
\frac{d c_{\beta}}{d t}=\frac{c_{\beta}}{m_{\mathrm{H}_{2} \mathrm{O}}}\left(1-\frac{1}{R}\right) \frac{d m_{\mathrm{cry}}}{d t}+k_{1} c_{\alpha}-k_{2} c_{\beta}+\dot{c}_{\beta}^{ \pm} \frac{m_{\mathrm{H}_{2} \mathrm{O}}^{ \pm}}{m_{\mathrm{H}_{2} \mathrm{O}}}+\left(c_{\beta}^{ \pm}-c_{\beta}\right) \frac{\dot{m}_{\mathrm{H}_{2} \mathrm{O}}^{ \pm}}{m_{\mathrm{H}_{2} \mathrm{O}}} .
$$

The crucial point about equations (2.13) and (2.15) is that on substituting (2.7), the state $m_{\text {cry }}$ disappears. Our study uses $\dot{c}_{\beta}^{ \pm}=0$ and $c_{\beta}^{-}=0$. Since in our experiment, we have only a source and no sink, then $\dot{m}_{\mathrm{H}_{2} \mathrm{O}}^{-}=0$, so that the source term is $c_{\beta}^{+} \frac{\dot{m}_{\mathrm{H}_{2} \mathrm{O}}^{+}}{m_{\mathrm{H}_{2} \mathrm{O}}}$, with $c_{\beta}^{+}$fixed. For the same reason, we are left with a source term $c_{\alpha}^{+} \frac{\dot{m}_{\mathrm{H}_{2} \mathrm{O}}^{+}}{m_{\mathrm{H}_{2} \mathrm{O}}}$ on the mass balance of $\beta$-lactose. We shall switch to the notation $q_{\mathrm{H}_{2} \mathrm{O}}:=\dot{m}_{\mathrm{H}_{2} \mathrm{O}}^{+}$, then the source term will given by $c_{\beta}^{+} \frac{q_{\mathrm{H}_{2} \mathrm{O}}}{m_{\mathrm{H}_{2} \mathrm{O}}}$. 


\subsection{Relating volume of slurry to masses}

The total volume of slurry $V(t)$ in the crystallizer is a dependent variable, which we now express as a function of the states $m_{\alpha}, m_{\beta}$, and $m_{\mathrm{H}_{2} \mathrm{O}}$. Observe that we have the relations

$$
V_{\alpha}=m_{\alpha} \rho_{\text {lac }, \alpha}^{-1}, V_{\beta}=m_{\beta} \rho_{\text {lac }, \beta}^{-1}, V_{\text {cry }}=m_{\text {cry }} \rho_{\text {cry }}^{-1}, V_{\mathrm{H}_{2} \mathrm{O}}=m_{\mathrm{H}_{2} \mathrm{O}} \rho_{\mathrm{H}_{2} \mathrm{O}}^{-1},
$$

with the obvious meanings, so that the total volume is

$$
V(t)=V_{\alpha}(t)+V_{\beta}(t)+V_{\mathrm{H}_{2} \mathrm{O}}(t)+V_{\text {cry }}(t) .
$$

Substituting the expressions from the previous sections,

$$
V_{\alpha}=c_{\alpha} m_{\mathrm{H}_{2} \mathrm{O}} \rho_{\mathrm{lac}, \alpha}^{-1}, \quad V_{\beta}=c_{\beta} m_{\mathrm{H}_{2} \mathrm{O}} \rho_{\mathrm{lac}, \beta}^{-1}, \quad V_{\mathrm{H}_{2} \mathrm{O}}=m_{\mathrm{H}_{2} \mathrm{O}} \rho_{\mathrm{H}_{2} \mathrm{O}}^{-1},
$$

and using

$$
V_{\text {cry }}(t)=\left(k_{v} \rho_{\text {cry }} V(t) \int_{0}^{\infty} n(L, t) L^{3} d L\right) \rho_{\text {cry }}^{-1}=k_{v} V(t) \int_{0}^{\infty} n(L, t) L^{3} d L,
$$

we obtain

$$
V(t)\left(1-k_{v} \int_{0}^{\infty} n(L, t) L^{3} d L\right)=m_{\mathrm{H}_{2} \mathrm{O}}(t)\left[c_{\alpha}(t) \rho_{\mathrm{lac}, \alpha}^{-1}+c_{\beta}(t) \rho_{\mathrm{lac}, \beta}^{-1}+\rho_{\mathrm{H}_{2} \mathrm{O}}^{-1}\right] .
$$

This may be written as

$$
V(t)=\frac{m_{\mathrm{H}_{2} \mathrm{O}}(t)}{1-k_{v} \int_{0}^{\infty} n(L, t) L^{3} d L}\left[\rho_{\mathrm{lac}, \alpha}^{-1} c_{\alpha}(t)+\rho_{\mathrm{lac}, \beta}^{-1} c_{\beta}(t)+\rho_{\mathrm{H}_{2} \mathrm{O}}^{-1}\right] .
$$

This expression will have to be substituted for $V(t)$ in the formulae below and above. The initial condition $V(0)=V_{0}$ now leads to

$$
\frac{m_{\mathrm{H}_{2} \mathrm{O}}(0)}{1-k_{v} \int_{0}^{\infty} n_{0}(L) L^{3} d L}\left[\rho_{\mathrm{lac}, \alpha}^{-1} c_{\alpha}(0)+\rho_{\mathrm{lac}, \beta}^{-1} c_{\beta}(0)+\rho_{\mathrm{H}_{2} \mathrm{O}}^{-1}\right]=V_{0},
$$

where

$$
m_{\mathrm{H}_{2} \mathrm{O}}(0)=m_{\mathrm{H}_{2} \mathrm{O}, 0},
$$

which when substituted into (2.20) gives the initial condition

$$
V_{0}=m_{\text {cry }, 0} \rho_{\text {cry }}^{-1}+m_{\mathrm{H}_{2} \mathrm{O}, 0}\left[\rho_{\text {lac }, \alpha}^{-1} c_{\alpha, 0}+\rho_{\text {lac }, \beta}^{-1} c_{\beta, 0}+\rho_{\mathrm{H}_{2} \mathrm{O}}^{-1}\right] .
$$

Using $m_{\alpha}=m_{\mathrm{H}_{2} \mathrm{O}} c_{\alpha}$ and $m_{\beta}=m_{\mathrm{H}_{2} \mathrm{O}} c_{\beta}$, we obtain

$$
m_{\alpha, 0}=m_{\mathrm{H}_{2} \mathrm{O}}(0) c_{\alpha}(0),
$$

and

$$
m_{\beta, 0}=m_{\mathrm{H}_{2} \mathrm{O}}(0) c_{\beta}(0)
$$


In addition, if we assume that $\alpha$-and $\beta$-lactose are initially at an equilibrium of mutarotation, we have to add the initial condition

$$
c_{\beta, 0}=k_{m}\left(T_{0}\right) c_{\alpha, 0}
$$

where

$$
T_{0}=T(0)
$$

is the initial temperature of the slurry. Clearly if $m_{\mathrm{H}_{2} \mathrm{O}, 0}$ and $c_{\alpha, 0}, c_{\beta, 0}$ are known, we also know $V_{0}$. Conversely, if $V_{0}$ and $c_{\alpha, 0}, c_{\beta, 0}$ are known, we can determine $m_{\mathrm{H}_{2} \mathrm{O}, 0}$. Likewise, since we assume that $\alpha$ and $\beta$ are initially at equilibrium of mutarotation, it suffices to know $V_{0}$ and $c_{\alpha, 0}+c_{\beta, 0}$ to reconstruct $m_{\mathrm{H}_{2} \mathrm{O}, 0}$. Quantities depending on temperature and initial values are given in Table 4 and Table 5.

\subsection{Energy balance}

The energy balance includes the internal heat produced by the crystallization reaction, and the heating and cooling system used to trigger and control the process. Altogether this involves the state $T(t)$ representing the temperature of the slurry, assumed homogeneous due to stirring, the temperature of the crystallizer jacket $T_{\text {jacket }}(t)$, and the set-point temperature $T_{\mathrm{sp}}(t)$, which is used as control input. We also need $T_{\text {feed }}$, the temperature of the feed, which we assume constant, and a reference temperature $T_{\text {ref }}=25^{\circ} \mathrm{C}$, needed to quantify the heating respectively cooling effect of the feed on the crystallizer temperature $T$; see Mersmann (2001). This leads to the equation

$$
\begin{array}{r}
\frac{d T(t)}{d t}=P_{1}(t)\left[-P_{2}(t)\left(T(t)-T_{\mathrm{ref}}\right)-\Delta H \frac{d m_{\mathrm{cry}}(t)}{d t}+U A(t)\left(T_{\text {jacket }}(t)-T(t)\right)\right. \\
\left.+q_{\mathrm{H}_{2} \mathrm{O}}(t)\left(C_{\mathrm{H}_{2} \mathrm{O}}^{p}+C_{\alpha}^{p} c_{\alpha}(0)+C_{\beta}^{p} c_{\beta}(0)\right)\left(T_{\text {feed }}-T_{\text {ref }}\right)\right],
\end{array}
$$

where

$$
\frac{d T_{\text {jacket }}(t)}{d t}=-a\left(T_{\text {jacket }}(t)-T_{\mathrm{sp}}(t)\right)
$$

was obtained through identification of the system where $a$ is determined experimentally in the laboratory. Note that $T_{\mathrm{sp}}(t)$ is used as a control input to regulate $T_{\text {jacket }}(t)$, and therefore indirectly $T(t)$, via the heat exchange between the jacket and the crystallizer through the contact surface $A(t)$, which is a dependent function of $V(t)$. The constants $C_{\mathrm{H}_{2} \mathrm{O}}^{p}, C_{\alpha}^{p}, C_{\beta}^{p}$ are the specific heat capacities, and $\Delta H$ is the heat of crystallization in $\mathrm{kJ} / \mathrm{kg}$, see McSweeney et al. (2009). We have used the abbreviations

$$
P_{1}(t)^{-1}=m_{\mathrm{H}_{2} \mathrm{O}}(t) C_{\mathrm{H}_{2} \mathrm{O}}^{p}+m_{\alpha}(t) C_{\alpha}^{p}+m_{\beta}(t) C_{\beta}^{p}+m_{\text {cry }}(t) C_{\text {cry }}^{p},
$$

and

$$
P_{2}(t)=\frac{d m_{\mathrm{H}_{2} \mathrm{O}}(t)}{d t} C_{\mathrm{H}_{2} \mathrm{O}}^{p}+\frac{d m_{\alpha}(t)}{d t} C_{\alpha}^{p}+\frac{d m_{\beta}(t)}{d t} C_{\beta}^{p}+\frac{d m_{\mathrm{cry}}(t)}{d t} C_{\text {cry }}^{p}
$$

with $m_{\alpha}=c_{\alpha} m_{\mathrm{H}_{2} \mathrm{O}}, m_{\beta}=c_{\beta} m_{\mathrm{H}_{2} \mathrm{O}}$ as before. 


\subsection{Mutarotation and saturation}

The mutarotation exchange coefficients $k_{1}, k_{2}$ depend on temperature via the Arrhenius law

$$
k_{2}(T)=k_{0} \exp \left(-\frac{E_{a}}{R_{g}(T+273.15)}\right), \quad k_{1}(T)=k_{2}(T) k_{m}(T),
$$

where $k_{0}, E_{a}$ are constants, $R_{g}$ is the gas constant, and where according to Mcleod (2007) $k_{m}$ follows the affine law

$$
k_{m}(T)=1.64-0.0027 \cdot T .
$$

The equilibrium of mutarotation therefore occurs at

$$
c_{\alpha, \text { sat }, \mathrm{eq}}(T)=\frac{\theta_{1} \exp \left(\theta_{2} T\right)}{100\left(1+k_{m}(T)\right)},
$$

where $\theta_{1}=10.9109$ and $\theta_{2}=0.02804$ are determined experimentally according to Mcleod (2007), so that the saturation level for the formation of $\alpha$-crystals is also temperature dependent and expressed as

$$
c_{\alpha, \text { sat }}\left(c_{\beta}, T\right)=c_{\alpha, \text { sat,eq }}(T)-F(T)\left(c_{\beta}-k_{m}(T) c_{\alpha, \text { sat,eq }}(T)\right),
$$

with $F(T)=0.0187 \cdot \exp (0.0236 \cdot T)$ a correction factor for $\alpha$-lactose solubility following a Visser type law according to Mcleod (2007). Note that the saturation concentration varies in time as $c_{\alpha, \text { sat }}\left(c_{\beta}(t), T(t)\right)$, because $c_{\beta}(t)$ and $T(t)$ vary in time.

\subsection{Nucleation and growth rates}

The nucleation and growth rates are based on phenomenological laws which are usually determined experimentally. Following Mcleod (2007), we used the birth rate

$$
B\left(c_{\alpha}, c_{\beta}, T\right)=k_{b} \exp \left(-\frac{B_{0}}{(T+273.15)^{3} \ln ^{2}\left(\frac{c_{\alpha}}{c_{\alpha, \text { sat }}\left(c_{\beta}, T\right)}\right)}\right)
$$

for $c_{\alpha}>c_{\alpha, \text { sat }}$, while $B\left(c_{\alpha}, c_{\beta}, T\right)=0$ for $c_{\alpha} \leqslant c_{\alpha, \text { sat }}\left(c_{\beta}, T\right)$. Constant $k_{b}$ given in Table 3 determines the unit of $B$, while the unit of $B_{0}$ is ${ }^{\circ} C$ (Mimouni, 2007; Mimouni A. et al., 2009).

Similarly, the growth rate was based on Mcleod (2007) and chosen as

$$
G\left(c_{\alpha}, c_{\beta}, T\right)=k_{g}\left(c_{\alpha}-c_{\alpha, \text { sat }}\left(c_{\beta}, T\right)\right)
$$

with unit determined by the unit of the growth coefficient $k_{g}$ in $m \cdot s^{-1}$. As we can see, $c_{\alpha}>c_{\alpha \text {,sat }}$ leads to $G>0$, in which case crystals grow, while $c_{\alpha}<c_{\alpha \text {,sat }}$ means crystals shrink.

\section{Main result}

In this section we present our main result, the global existence and uniqueness theorem. The complete model for which this will be proved includes the population balance equation (2.1), coupled with the mass balances equations (2.7), (2.11), (2.12), (2.14), and the energy balance (2.27). The initial condition for the population balance is $n(L, 0)=n_{0}(L)$, while the initial conditions of the mass balances (2.7), 


\begin{tabular}{||c|c|c||}
\hline \hline$n(L, t)$ & number $/ m \cdot m^{3}$ & particle size distribution \\
\hline$m_{\alpha}(t)$ & $\mathrm{kg}$ & mass of $\alpha$-lactose in solution \\
\hline$m_{\beta}(t)$ & $\mathrm{kg}$ & mass of $\beta$-lactose in solution \\
\hline$V(t)$ & $\mathrm{m}^{3}$ & volume of slurry \\
\hline$A(t)$ & $\mathrm{m}^{2}$ & contact surface \\
\hline
\end{tabular}

Table 2. Units of dynamic quantities

(2.11), (2.12), (2.14), and the energy balance (2.27) are given by the expressions (2.8), (2.21), (2.23), (2.24) and (2.26).

Let us next present the hypotheses under which global existence of a solution will be shown. These are motivated by the physics of the process, leading to prior bounds on mass, volume, and temperature. A detailed discussion of theses hypotheses will be given in the prior estimate section 5 .

- Restriction of the total volume of slurry by way of a control constraint limiting the cumulative feed rate via

$$
\left(H_{1}\right) \quad \int_{0}^{t} q_{\mathrm{H}_{2} \mathrm{O}}(\tau) d \tau \leqslant \frac{1}{\left(c_{\alpha, 0}+c_{\beta, 0}+1\right)}\left[\frac{V_{\max }-V_{0}}{\left.\rho_{\alpha}^{-1}+\rho_{\beta}^{-1}+\rho_{\mathrm{H}_{2} \mathrm{O}^{-1}+\rho_{\text {cry }}-1}\right]} ;\right.
$$

- An allowed range for the set-point temperature, corresponding to a control constraint

$$
\left(H_{2}\right) \quad \underline{T} \leqslant T_{\mathrm{sp}}(t) \leqslant \bar{T} \quad \text { for } t \geqslant 0 ;
$$

- An assumption about the initial mixture of water and lactose in the crystallizer

$$
\left(H_{3}\right) \quad 0<m_{\alpha}(0)+m_{\beta}(0)<\left(\frac{M_{\text {cry }}}{M_{\alpha}}-1\right)^{-1} m_{\mathrm{H}_{2} \mathrm{O}}(0) ;
$$

- Moreover, mathematically motivated hypotheses on the breakage terms $a$ and $b$ :

$$
\begin{aligned}
& \left(H_{4}\right) \quad\|a\|_{\infty}:=\max _{0 \leqslant L<\infty} a(L)<+\infty, \quad\|a\|_{L}=\sup _{0 \leqslant L<L^{\prime}}\left|\frac{a(L)-a\left(L^{\prime}\right)}{L-L^{\prime}}\right|<\infty, \\
& \left(H_{5}\right) \quad\|b\|_{\infty}:=\max _{0 \leqslant L \leqslant L^{\prime}} b\left(L^{\prime}, L\right)<+\infty, \quad\|b\|_{L}:=\sup _{L \geqslant 0} \sup _{L \leqslant L^{\prime}<L^{\prime \prime}}\left|\frac{b\left(L, L^{\prime}\right)-b\left(L, L^{\prime \prime}\right)}{L^{\prime}-L^{\prime \prime}}\right|<\infty, \\
& \left(H_{6}\right) \quad \int_{0}^{L^{\prime}} \beta\left(L^{\prime}, L\right) L^{3} d L \leqslant c L^{\prime 3} \quad \text { for some } c>0 .
\end{aligned}
$$

A typical example of $a$ and $b$ satisfying these hypotheses are for instance

$$
a(L)=1, \quad b\left(L, L^{\prime}\right)= \begin{cases}\frac{6 L^{2}}{L^{\prime 3}} & \text { if } L \geqslant L^{\prime} \\ 0 & \text { else }\end{cases}
$$

proposed in Marchisio et al. O Other typical breakage rate and daughter distributions based on experiments may for instance be found in Marchisio et al. (Marchisio et al., 2002), Reynolds et al. (Reynolds et al., 2005), or Ziff and McGrady (Ziff, 1985). 


\begin{tabular}{|c|c|c|c|}
\hline quantity & symbol & value & unit \\
\hline maximum volume & $V_{\max }$ & 0.01 & $m^{3}$ \\
\hline initial volume & $V_{0}$ & 0.0015 & $m^{3}$ \\
\hline crystal density & $\rho_{\text {cry }}$ & 1545 & $\mathrm{~kg} \cdot \mathrm{m}^{-3}$ \\
\hline$\alpha$-lactose density & $\rho_{\text {lac }, \alpha}$ & 1545 & $\mathrm{~kg} \cdot \mathrm{m}^{-3}$ \\
\hline$\beta$-lactose density & $\rho_{\mathrm{lac}, \beta}$ & 1590 & $\mathrm{~kg} \cdot \mathrm{m}^{-3}$ \\
\hline water density & $\rho_{\mathrm{H}_{2} \mathrm{O}}$ & 1000 & $\mathrm{~kg} \cdot \mathrm{m}^{-3}$ \\
\hline volumic shape factor & $k_{v}$ & 0.523598 & - \\
\hline ratio of molar masses & $R$ & 1.0525 & - \\
\hline universal gas constant & $R_{g}$ & 8.314 & $\mathrm{~J} / \mathrm{K} / \mathrm{mol}$ \\
\hline birth rate coefficient & $k_{b}$ & $10^{10}$ & number $\cdot m^{-3} s^{-1}$ \\
\hline nucleation constant & $B_{0}$ & $1.4687^{8}$ & - \\
\hline nucleation exponent & $b$ & 2 & - \\
\hline growth rate coefficient & $k_{g}$ & $1.18 \cdot 10^{-7}$ & $m \cdot s^{-1}$ \\
\hline growth exponent & $g$ & 1 & - \\
\hline activation energy & $E_{a}$ & $7.4 \cdot 10^{4}$ & $J$ \\
\hline kinetic mutarotation constant & $k_{0}$ & $2.25 \cdot 10^{8}$ & $s^{-1}$ \\
\hline heat of crystallization & $\Delta H$ & -43.1 & $k J / k g$ \\
\hline heat transfer coefficient & $U$ & 300 & $W / m^{2} / K$ \\
\hline heat capacity of water & $C_{\mathrm{H}_{2} \mathrm{O}}^{p}$ & 4180.5 & $J / \mathrm{kg} / \mathrm{K}$ \\
\hline heat capacity of $\alpha$-crystal & $C_{\mathrm{cry}}^{p}$ & 1251 & $\mathrm{~J} / \mathrm{kg} / \mathrm{K}$ \\
\hline heat capacity of $\alpha$-lactose & $C_{\alpha}^{p}$ & 1193 & $\mathrm{~J} / \mathrm{kg} / \mathrm{K}$ \\
\hline heat capacity of $\beta$-lactose & $C_{\beta}^{p}$ & 1193 & $J / \mathrm{kg} / \mathrm{K}$ \\
\hline fraction of $\alpha$-lactose in feed & $c_{\alpha}^{+}$ & 0.521 & $\mathrm{~kg} / \mathrm{kg}$ water \\
\hline fraction of $\beta$-lactose in feed & $c_{\beta}^{+}$ & 0.359 & $\mathrm{~kg} / \mathrm{kg}$ water \\
\hline mass of seed & $m_{\text {cry }, 0}$ & 0.1 & $k g$ \\
\hline reference temperature & $T_{\text {ref }}$ & 25 & ${ }^{\circ} \mathrm{C}$ \\
\hline feed temperature & $T_{\text {feed }}$ & 20 & ${ }^{\circ} \mathrm{C}$ \\
\hline identified jacket heat coefficient & $a$ & 0.0019 & - \\
\hline
\end{tabular}

Table 3. Numerical constants of industrial crystallizer

Let us now outline the idea of proof of our main result, which uses the method of characteristics with a fixed point argument for an operator $\mathscr{Q}$, which will act as a contraction with respect to a specific metric. This operator $\mathscr{Q}$ is defined by:

$$
\mathscr{Q} \mathbf{x}=\widetilde{\mathbf{x}}=\left(\widetilde{m}_{\alpha}, \widetilde{m}_{\beta}, \widetilde{m}_{\mathrm{H}_{2} \mathrm{O}}, \widetilde{m}_{\mathrm{cry}}, \widetilde{T}, \widetilde{\mu}_{2}, \widetilde{\mu}_{1}, \widetilde{\mu}_{0}, \widetilde{w}\right) .
$$

where $\mathbf{x}=\left(m_{\alpha}, m_{\beta}, m_{\mathrm{H}_{2} \mathrm{O}}, T, m_{\text {cry }}, \mu_{2}, \mu_{1}, \mu_{0}, w\right)$ is an element of the space

$$
\mathbf{F}=C\left[0, t_{f}\right]^{8} \times C\left(\mathbb{R}^{+} \times\left[0, t_{f}\right]\right) \cap \mathscr{L}_{u}^{1}\left(\mathbb{R}^{+} \times\left[0, t_{f}\right], h(L) d L\right),
$$

where the elements of $\widetilde{\mathbf{x}}$ are defined by way of the characteristics which will be detailed in the section introducing characteristics. The space $\mathbf{F}$ and the operator $\mathscr{Q}$ will be detailed in the section global existence and uniqueness. The expressions of the elements of $\mathbf{x}$ and $\widetilde{\mathbf{x}}$ will be given in section 6 . Now our main result, whose proof we will be completed in section 6 , is the following 


\begin{tabular}{||c|c|c||}
\hline \hline quantity & symbol & unit \\
\hline mutarotation exchange fraction & $k_{m}(T)$ & - \\
mutarotation $\alpha \rightarrow \beta$ exchange rate & $k_{1}(T)$ & $s^{-1}$ \\
mutarotation $\beta \rightarrow \alpha$ exchange rate & $k_{2}(T)$ & $s^{-1}$ \\
saturation concentration at equilibrium of mutarotation & $c_{\alpha, \text { sat,eq }}(T)$ & - \\
saturation concentration & $c_{\alpha, \text { sat }}\left(c_{\beta}, T\right)$ & - \\
crystal growth rate & $G\left(c_{\alpha}, c_{\beta}, T\right)$ & $m s^{-1}$ \\
crystal birth rate & $B\left(c_{\alpha}, c_{\beta}, T\right)$ & number $\cdot m^{-3} s^{-1}$ \\
\hline \hline
\end{tabular}

Table 4. Quantities depending on temperature

THEOREM 3.1 Let hypotheses $\left(H_{1}\right)-\left(H_{3}\right)$ be satisfied, and suppose the initial condition of the crystallizer respects the global volume bound $V_{\max }$. Assume further that the breakage kernel satisfies the hypotheses $\left(H_{4}\right)-\left(H_{6}\right)$. Then the crystallizer system $(2.1),(2.11),(2.13),(2.15),(2.27)$ has a unique global solution on $[0, \infty)$.

\section{Introducing characteristics}

In this chapter we present a transformation of the formulation of the model by introducing the moments and the characteristic curves.

\subsection{Moments}

We consider the population balance equation

$$
\frac{\partial(V(t) n(L, t))}{\partial t}=-G\left(c_{\alpha}(t), c_{\beta}(t), T(t)\right) \frac{\partial V(t) n(L, t)}{\partial L}-a(L) V(t) n(L, t)+w(L, t)
$$

where

$$
w(L, t)=\int_{L}^{\infty} a\left(L^{\prime}\right) b\left(L^{\prime}, L\right) V(t) n\left(L^{\prime}, t\right) d L^{\prime}
$$

is the source term due to breakage and attrition. The boundary condition is

$$
n(0, t)=\frac{B\left(c_{\alpha}(t), c_{\beta}(t), T(t)\right)}{G\left(c_{\alpha}(t), c_{\beta}(t), T(t)\right)}, \quad t \geqslant 0
$$

and the initial condition is

$$
n(L, 0)=n_{0}(L), \quad L \in[0, \infty)
$$

Then we can define

$$
w_{0}=w(L, 0)=\int_{L}^{\infty} a\left(L^{\prime}\right) b\left(L^{\prime}, L\right) V(0) n_{0}\left(L^{\prime}\right) d L^{\prime} .
$$

Now, we consider the $3 \mathrm{rd}$ moment of $w(\cdot, t)$, for which we obtain the estimate

$$
\begin{aligned}
\int_{0}^{\infty} w(L, t) L^{3} d L & =V(t) \int_{0}^{\infty} L^{3} \int_{L}^{\infty} a\left(L^{\prime}\right) b\left(L^{\prime}, L\right) n\left(L^{\prime}, t\right) d L^{\prime} d L \\
& =V(t) \int_{0}^{\infty} a\left(L^{\prime}\right) n\left(L^{\prime}, t\right)\left(\int_{0}^{L^{\prime}} L^{3} b\left(L^{\prime}, L\right) d L\right) d L^{\prime} .
\end{aligned}
$$


Under (2.6), and with $a(\cdot) \in L^{\infty}$, we now derive the estimate

$$
\int_{0}^{\infty} w(L, t) L^{3} d L \leqslant\|a\|_{\infty} \rho^{-1} k_{v}^{-1} m_{\mathrm{cry}}(t)
$$

where $m_{\text {cry }}(t)=\rho k_{v} \int_{0}^{\infty} V(t) n(L, t) L^{3} d L$ is the total crystal mass.

The population balance is coupled with the mass balance of $\alpha$-lactose, the mass balance of $\beta$-lactose and the energy balance equations.

We start by solving (2.11) with respect to $m_{\mathrm{H}_{2} \mathrm{O}}(t),(2.13)$ with respect to $c_{\alpha}(t),(2.15)$ with respect to $c_{\beta}(t)$ and (2.27) with respect to $T(t)$, knowing that $m_{\text {cry }}(t)=k_{\nu} \rho_{\text {cry }} \int_{0}^{\infty} V(t) n(L, t) L^{3} d L$. For the concentration $c_{\alpha}$ the mass balance of $\alpha$-lactose gives

$$
\begin{aligned}
c_{\alpha}(t) & =\left[c_{\alpha, 0}+\int_{0}^{t}\left(k_{2}(T(\tau)) c_{\beta}(\tau)+\frac{q_{\mathrm{H}_{2} \mathrm{O}}(\tau) c_{\alpha, 0}}{m_{\mathrm{H}_{2} \mathrm{O}}(\tau)}-\frac{m_{\mathrm{cry}}^{\prime}(\tau)}{R m_{\mathrm{H}_{2} \mathrm{O}}(\tau)}\right) e^{-\int_{0}^{\tau}\left(-k_{1}(T(s))-\frac{q_{\mathrm{H}_{2}} \mathrm{O}^{(s)}}{m_{\mathrm{H}_{2}} \mathrm{O}^{(s)}}+\frac{\left(1-\frac{1}{m}\right) m_{\mathrm{cry}}^{\prime}(s)}{m_{\mathrm{H}_{2}} \mathrm{O}^{(s)}}\right) d s} d \tau\right] \\
& \times e^{\int_{0}^{t}\left(-k_{1}(T(\tau))-\frac{q_{\mathrm{H}_{2} \mathrm{O}}(\tau)}{m_{\mathrm{H}_{2} \mathrm{O}}(\tau)}+\frac{\left(1-\frac{1}{R}\right) m_{\mathrm{cry}}^{\prime}(\tau)}{m_{\mathrm{H}_{2} \mathrm{O}}(\tau)}\right) d \tau}
\end{aligned}
$$

using $c_{\alpha, 0}=c_{\alpha}(0)$. Similarly, the mass balance of $\beta$-lactose in terms of the concentration $c_{\beta}$ gives

$$
\begin{aligned}
& c_{\beta}(t)=\left[c_{\beta, 0}+\int_{0}^{t}\left(k_{1}(T(\tau)) c_{\alpha}(\tau)+\frac{q_{\mathrm{H}_{2} \mathrm{O}}(\tau)}{m_{\mathrm{H}_{2} \mathrm{O}}(\tau)} c_{\beta, 0}\right) e^{-\int_{0}^{\tau}\left(-k_{2}(T(s))-\frac{q_{\mathrm{H}_{2}} \mathrm{O}^{(s)}}{m_{\mathrm{H}_{2}} \mathrm{O}^{(s)}}+\frac{\left(1-\frac{1}{R}\right)}{m_{\mathrm{H}_{2}} \mathrm{O}^{(s)}} m_{\mathrm{cry}}^{\prime}(s)\right)} d s\right] \\
& \times e^{\int_{0}^{t}\left(-k_{2}(T(\tau))-\frac{q_{\mathrm{H}_{2} \mathrm{O}}(\tau)}{m_{\mathrm{H}_{2}} \mathrm{O}(\tau)}+\frac{\left(1-\frac{1}{R}\right)}{m_{\mathrm{H}_{2}} \mathrm{O}(\tau)} m_{\mathrm{cry}}^{\prime}(\tau)\right) d \tau}
\end{aligned}
$$

using $c_{\beta, 0}=c_{\beta}(0)$. Equivalently, we may solve directly for the masses to obtain

$$
m_{\alpha}(t)=\left[\int_{0}^{t}\left(k_{2}(T(\tau)) m_{\beta}(\tau)-\frac{1}{R} m_{\mathrm{cry}}^{\prime}(\tau)+c_{\alpha, 0} q_{\mathrm{H}_{2} \mathrm{O}}(\tau)\right) e^{\int_{0}^{\tau} k_{1}(T(s)) d s} d \tau+m_{\alpha, 0}\right] e^{\int_{0}^{t}-k_{1}(T(s)) d s}
$$

using $m_{\alpha}=m_{\mathrm{H}_{2} \mathrm{O}} c_{\alpha}$ and $m_{\beta}=m_{\mathrm{H}_{2} \mathrm{O}} c_{\beta}$. By solving (2.15) with respect to $m_{\beta}$ using variation of the constant, we obtain

$$
m_{\beta}(t)=\left[\int_{0}^{t}\left(k_{1}(T(\tau)) m_{\alpha}(\tau)+c_{\beta, 0} q_{\mathrm{H}_{2} \mathrm{O}}(\tau)\right) e^{\int_{0}^{\tau} k_{2}(T(s)) d s} d \tau+m_{\beta, 0}\right] e^{\int_{0}^{t}-k_{2}(T(s)) d s}
$$

For the mass balance of solvent we have

$$
m_{\mathrm{H}_{2} \mathrm{O}}(t)=\int_{0}^{t}\left[-\left(1-\frac{1}{R}\right) m_{\mathrm{cry}}^{\prime}(\tau)+q_{\mathrm{H}_{2} \mathrm{O}}(\tau)\right] d \tau+m_{\mathrm{H}_{2} \mathrm{O}, 0},
$$


where $m_{\mathrm{H}_{2} \mathrm{O}, 0}=m_{\mathrm{H}_{2} \mathrm{O}}(0)$. Finally, the energy balance is

$$
\begin{aligned}
T(t) & =e^{\int_{0}^{t}\left(-P_{1}(\tau) P_{2}(\tau)-U A(\tau)\right) d \tau}\left[T_{0}+\int_{0}^{t}\left(P _ { 1 } ( \tau ) \left(P_{2}(\tau) T_{\text {ref }}-\Delta H m_{\text {cry }}^{\prime}(\tau)\right.\right.\right. \\
& \left.\left.+U A(\tau) T_{\text {jacket }}(\tau)+q_{\mathrm{H}_{2} \mathrm{O}}(\tau)\left(C_{\mathrm{H}_{2} \mathrm{O}}^{p}+C_{\alpha}^{p} c_{\alpha, 0}+C_{\beta}^{p} c_{\beta, 0}\right)\left(T_{\text {feed }}-T_{\text {ref }}\right)\right)\right) \\
& \left.e^{-\int_{0}^{\tau}\left(-P_{1}(s) P_{2}(s)-U A(s)\right) d s} d \tau\right]
\end{aligned}
$$

where $T_{0}=T(0)$ and $m_{\alpha}=c_{\alpha} m_{\mathrm{H}_{2} \mathrm{O}}, m_{\beta}=c_{\beta} m_{\mathrm{H}_{2} \mathrm{O}}$. By using the third moment $\mu_{3}(t)=\int_{0}^{\infty} V(t) n(L, t) L^{3} d L$, we have $m_{\text {cry }}(t)=\rho k_{v} \mu_{3}(t)$ and $m_{\text {cry }}^{\prime}(t)=\rho k_{v} \mu_{3}^{\prime}(t)$.

\subsection{Characteristic curves}

Now we are ready to introduce characteristic curves as follows (Evans, 2001). For $t_{0}$ and $L_{0}$ fixed we let $\phi_{t_{0}, L_{0}}$ be the solution of the initial value problem

$$
\phi^{\prime}(t)=G\left(c_{\alpha}(t), c_{\beta}(t), T(t)\right), \quad \phi\left(t_{0}\right)=L_{0} .
$$

Since the right hand side does not depend on $L$, we have explicitly

$$
\phi_{t_{0}, L_{0}}(t)=L_{0}+\int_{t_{0}}^{t} G\left(c_{\alpha}(\tau), c_{\beta}(\tau), T(\tau)\right) d \tau
$$

We write specifically $z(t):=\phi_{0,0}(t)$. Now we introduce a family of functions $N_{t, L}$ which we use later to define $V(t) n(L, t)$ via $N_{t_{0}, L_{0}}(t):=V(t) n\left(\phi_{t_{0}, L_{0}}(t), t\right)$. We let $L=\phi_{t_{0}, L_{0}}(t)$, then $N_{t_{0}, L_{0}}$ satisfies

$$
\begin{aligned}
N_{t_{0}, L_{0}}^{\prime}(t) & =\frac{\partial(V(t) n(L, t))}{\partial L} \phi_{t_{0}, L_{0}}^{\prime}(t)+\frac{\partial(V(t) n(L, t))}{\partial t} \\
& =\frac{\partial(V(t) n(L, t))}{\partial L} G\left(c_{\alpha}(t), c_{\beta}(t), T(t)\right)+\frac{\partial(V(t) n(L, t))}{\partial t} .
\end{aligned}
$$

Therefore (4.1) transforms into

$$
N_{t_{0}, L_{0}}^{\prime}(t)=-a\left(\phi_{t_{0}, L_{0}}(t)\right) N_{t_{0}, L_{0}}(t)+w\left(\phi_{t_{0}, L_{0}}(t), t\right),
$$

and we consequently use these ODEs to define the functions $N_{t, L}$. Integration of (4.15) gives

$$
\begin{aligned}
N_{t_{0}, L_{0}}(t) & =\left(N_{t_{0}, L_{0}}\left(t_{0}\right)+\int_{t_{0}}^{t} w\left(\phi_{t_{0}, L_{0}}(\tau), \tau\right) \exp \left\{\int_{t_{0}}^{\tau} a\left(\phi_{t_{0}, L_{0}}(\sigma)\right) d \sigma\right\} d \tau\right) \\
& \times \exp \left\{-\int_{t_{0}}^{t} a\left(\phi_{t_{0}, L_{0}}(\tau)\right) d \tau\right\}
\end{aligned}
$$

We can exploit this for two possible situations, where $N_{t_{0}, L_{0}}\left(t_{0}\right)$ can be given an appropriate value.

Before putting this to work, we will need two auxiliary functions $\tau$ and $\xi$, which are easily defined using the characteristics. First we define $\tau=\tau(t, L)$ implicitly by

$$
\phi_{\tau, 0}(t)=L, \text { or equivalently, } \phi_{t, L}(\tau)=0,
$$


or again,

$$
\int_{\tau(t, L)}^{t} G\left(c_{\alpha}(\sigma), c_{\beta}(\sigma), T(\sigma)\right) d \sigma=L
$$

Then we define $\xi=\xi(t, L)=\phi_{t, L}(0)$, which gives $\xi=L+\int_{t}^{0} G\left(c_{\alpha}(\tau), c_{\beta}(\tau), T(\tau)\right) d \tau$. Using $N_{t, L}$, respectively (4.16), we can now define

$$
V\left(t_{0}\right) n\left(L_{0}, t_{0}\right)=\left\{\begin{array}{c}
\left(V\left(t_{0}\right) \frac{B\left(c_{\alpha}\left(\tau_{0}\right), c_{\beta}\left(\tau_{0}\right), T\left(\tau_{0}\right)\right)}{G\left(c_{\alpha}\left(\tau_{0}\right), c_{\beta}\left(\tau_{0}\right), T\left(\tau_{0}\right)\right)}+\int_{\tau_{0}}^{t_{0}} w\left(\phi_{\tau_{0}, 0}(s), s\right) \exp \left\{\int_{\tau_{0}}^{s} a\left(\phi_{\tau_{0}, 0}(\sigma)\right) d \sigma\right\} d s\right) \\
\times \exp \left(-\int_{\tau_{0}}^{t_{0}} a\left(\phi_{\tau_{0}, 0}(s)\right) d s\right), \text { if } L_{0}<z\left(t_{0}\right) \\
\left(V\left(t_{0}\right) n_{0}\left(\phi_{t_{0}, L_{0}}(0)\right)+\int_{0}^{t_{0}} w\left(\phi_{t_{0}, L_{0}}(s), s\right) \exp \left\{\int_{0}^{s} a\left(\phi_{t_{0}, L_{0}}(\sigma)\right) d \sigma\right\} d s\right) \\
\times \exp \left(-\int_{0}^{t_{0}} a\left(\phi_{t_{0}, L_{0}}(s)\right) d s\right), \text { if } L_{0} \geqslant z\left(t_{0}\right)
\end{array}\right.
$$

where $\tau_{0}=\tau\left(t_{0}, L_{0}\right)$ and $t_{0} \in\left[0, t_{f}\right]$. The formula is justified as follows. Let $t_{0}, L_{0}$ be such that $L_{0}<$ $z\left(t_{0}\right)=\phi_{0,0}\left(t_{0}\right)$. This is the case where $\tau_{0}=\tau\left(t_{0}, L_{0}\right)>0$. Here we consider equation (4.15) for $N_{\tau_{0}, 0}$ with initial value $N_{\tau_{0}, 0}\left(\tau_{0}\right)=V\left(\tau_{0}\right) n\left(\phi_{\tau_{0}, 0}\left(\tau_{0}\right), \tau_{0}\right)=V\left(\tau_{0}\right) n\left(0, \tau_{0}\right)=V\left(\tau_{0}\right) B\left(c\left(\tau_{0}\right)\right) / G\left(c\left(\tau_{0}\right)\right)$. This uses the fact that $\phi_{\tau_{0}, 0}\left(\tau_{0}\right)=0$ according to the definition of $\phi_{\tau, 0}$. Integration clearly gives the upper branch of (4.19).

Next consider $t_{0}, L_{0}$ such that $L_{0} \geqslant z\left(t_{0}\right)$. Then $\tau_{0}<0$, so that we do not want to use it as initial value. We therefore apply (4.15), (4.16) to $N_{t_{0}, L_{0}}$, now with initial time $t=0$. Then we get

$$
\begin{aligned}
N_{t_{0}, L_{0}}\left(t_{0}\right) & =\left(N_{t_{0}, L_{0}}(0)+\int_{0}^{t_{0}} w\left(\phi_{t_{0}, L_{0}}(s), s\right) \exp \left\{\int_{0}^{s} a\left(\phi_{t_{0}, L_{0}}(\sigma)\right) d \sigma\right\} d s\right) \\
& \times \exp \left(-\int_{0}^{t_{0}} a\left(\phi_{t_{0}, L_{0}}(s)\right) d s\right) .
\end{aligned}
$$

Here $N_{t_{0}, L_{0}}(0)=V(0) n\left(\phi_{t_{0}, L_{0}}(0), 0\right)=V(0) n_{0}\left(\phi_{t_{0}, L_{0}}(0)\right)$, so we get the lower branch of (4.19) all right. This justifies the formula and completes the definition of the characteristic curves and the representation of $V(t) n(L, t)$ via the characteristics.

\section{A priori estimates}

In this section we discuss two hypotheses on the control inputs $T_{\mathrm{sp}}$ and $q_{\mathrm{H}_{2} \mathrm{O}}$, which lead to a priori estimates, under which later on global existence of a solution will be shown. These conditions are motivated by the physics of the process and lead to bounds on mass, volume, and temperature. Note that we do not get a priori estimates on surface, length and number of solids, which as we shall see presents a difficulty when proving global existence of solutions. 


\subsection{Hypothesis on total volume using the feed rate}

The total mass of slurry $M$ in the crystallizer is given by

$$
M(t)=m_{\alpha}(t)+m_{\beta}(t)+m_{\mathrm{H}_{2} \mathrm{O}}(t)+m_{\mathrm{cry}}(t)
$$

hence $M(0)=m_{\alpha}(0)+m_{\beta}(0)+m_{\mathrm{H}_{2} \mathrm{O}}(0)+m_{\text {cry }}(0)$. The total volume of slurry $V$ is

$$
V(t)=V_{\alpha}(t)+V_{\beta}(t)+V_{\mathrm{H}_{2} \mathrm{O}}(t)+V_{\text {cry }}(t)=\frac{m_{\alpha}(t)}{\rho_{\alpha}}+\frac{m_{\beta}(t)}{\rho_{\beta}}+\frac{m_{\mathrm{H}_{2} \mathrm{O}}(t)}{\rho_{\mathrm{H}_{2} \mathrm{O}}}+\frac{m_{\text {cry }}(t)}{\rho_{\text {cry }}} .
$$

Since we are only allowed a maximum volume $V_{\max }$ of slurry in the crystallizer, we have to steer the process such that $V(t) \leqslant V_{\max }$ at all times $t$. Naturally, this can be arranged by a suitable control of the feed rate, and this is expressed by hypothesis $\left(H_{1}\right)$ :

LEMMA 5.1 Suppose the feed rate $q_{\mathrm{H}_{2} \mathrm{O}}$ satisfies the constraint

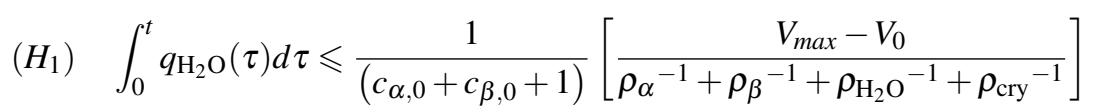

at all times $t \geqslant 0$. Then the total volume of slurry $V(t)$ satisfies $V(t) \leqslant V_{\max }$.

Proof. From (5.1) we obviously have

$$
M^{\prime}(t)=m_{\alpha}^{\prime}(t)+m_{\beta}^{\prime}(t)+m_{\mathrm{H}_{2} \mathrm{O}}^{\prime}(t)+m_{\mathrm{cry}}^{\prime}(t) .
$$

Replacing $m_{\mathrm{H}_{2} \mathrm{O}}^{\prime}, m_{\alpha}^{\prime}$ and $m_{\beta}^{\prime}$ in (5.4) by their expressions (2.11), (2.12) and (2.14), we obtain

$$
M^{\prime}(t)=\left(c_{\alpha, 0}+c_{\beta, 0}+1\right) q_{\mathrm{H}_{2} \mathrm{O}}(t)
$$

which on integration gives

$$
\int_{0}^{t} q_{\mathrm{H}_{2} \mathrm{O}}(\tau) d \tau=\frac{M(t)-M(0)}{c_{\alpha, 0}+c_{\beta, 0}+1}
$$

for every $t>0$. Hence, using the hypothesis $\left(H_{1}\right)$ and (5.6), we obtain

$$
M(t) \leqslant \frac{V_{\max }}{\rho_{\alpha}^{-1}+\rho_{\beta}^{-1}+\rho_{\mathrm{H}_{2} \mathrm{O}}^{-1}+\rho_{\text {cry }}{ }^{-1}} .
$$

Using (5.1) and (5.2), this implies $V(t) \leqslant V_{\max }$.

In a practical process, $q_{\mathrm{H}_{2} \mathrm{O}}$ could be steered by feedback to avoid overflow of the crystallizer.

\subsection{Hypothesis on set-point temperature}

As we have seen, bounding the feed rate via $\left(H_{1}\right)$ gives a bound on the total volume of slurry, and also on the total mass, namely

$$
M(t) \leqslant M_{\max }=\frac{V_{\max }}{\rho_{\alpha}^{-1}+\rho_{\beta}^{-1}+\rho_{\mathrm{H}_{2} \mathrm{O}}^{-1}+\rho_{\text {cry }}{ }^{-1}} .
$$


Now we also need to propose a hypothesis concerning the regulation of temperature, where we specify a range

$$
\left(H_{2}\right) \quad \underline{T} \leqslant T_{\mathrm{sp}}(t) \leqslant \bar{T} \quad \text { for } t \geqslant 0
$$

for the set-point temperature. On the one hand this reflects obvious material constraints on the equipment, but more importantly, we have to assure that the regulated temperature of slurry $T(t)$ stays in the range where $\alpha$-lactose crystallizes, i.e., $T \leqslant 90^{\circ}$. We start by deducing a bound on the jacket temperature.

LEMmA 5.2 Suppose the set-point temperature satisfies $\left(\mathrm{H}_{2}\right)$. Then the temperature of the jacket satisfies

$$
T_{\text {low }} \leqslant T_{\text {jacket }}(t) \leqslant T_{\text {high }}
$$

at all times $t$, where $T_{\text {low }}=T_{\text {jacket }}(0)+\underline{T}$ and $T_{\text {high }}=T_{\text {jacket }}(0)+\bar{T}$.

Proof. Solving the energy balance (2.28) with respect to $T(t)$ using variation of the constant gives

$$
T_{\text {jacket }}(t)=\left[\int_{0}^{t} a T_{\mathrm{sp}}(\tau) e^{\int_{0}^{\tau} a d s} d \tau+T_{\text {jacket }}(0)\right] e^{-\int_{0}^{t} a d s} .
$$

Hence, using the hypothesis $\left(H_{2}\right)$ and ( 5.11), we obtain

$$
e^{-a t} T_{\text {jacket }}(0)+\underline{T} \leqslant T_{\text {jacket }}(t) \leqslant T_{\text {jacket }}(0)+\bar{T}
$$

for $t \geqslant 0$, which proves the claim.

LEMma 5.3 Suppose the set-point temperature satisfies $\left(H_{2}\right)$, and the feed rate satisfies $\left(H_{1}\right)$. Then there exist bounds $T_{l}, T_{h}$ such that the temperature of slurry satisfies $T_{l} \leqslant T(t) \leqslant T_{h}$ at all times $t \geqslant 0$. In particular, it can be assured that $T(t) \leqslant 90^{\circ}$, so that only $\alpha$-lactose crystallizes.

Proof. Solving the energy balance (2.27) with respect to $T(t)$ using variation of the constant, we obtain

$$
\begin{aligned}
T(t)= & \int_{0}^{t} P_{1}(\tau)\left[\left(P_{2}(\tau)-\theta(\tau)\right) T_{\text {ref }}-\Delta H m_{\text {cry }}^{\prime}(\tau)+U A(\tau) T_{\text {jacket }}(\tau)+\theta(\tau) T_{\text {feed }}\right] \\
& \times e^{-\int_{\tau}^{t}\left(P_{1}(\tau) P_{2}(s)+U A(s)\right) d s} d \tau+T_{0} e^{-\int_{0}^{t}\left(P_{1}(s) P_{2}(s)+U A(s)\right) d s},
\end{aligned}
$$

where $\theta(\tau):=q_{\mathrm{H}_{2} \mathrm{O}}(\tau)\left(C_{\mathrm{H}_{2} \mathrm{O}}^{p}+C_{\alpha}^{p} c_{\alpha}(0)+C_{\beta}^{p} c_{\beta}(0)\right)$ and $P_{1}(t), P_{2}(t)$ are given by (2.29), (2.30). Substituting the expressions of $m_{\mathrm{H}_{2} \mathrm{O}}^{\prime}(t), m_{\alpha}^{\prime}(t), m_{\beta}^{\prime}(t)$ and $m_{\text {cry }}^{\prime}(t)$ in (2.30), we obtain

$$
P_{2}(t)=\sigma m_{\mathrm{cry}}^{\prime}(t)+\theta(t)
$$

where $\sigma:=C_{\mathrm{cry}}^{p}-C_{\mathrm{H}_{2} \mathrm{O}}^{p}\left(1-R^{-1}\right)-C_{\alpha}^{p} R^{-1}<0$ and $\theta(t)$ as above.

Since the temperature of the jacket satisfies $T_{\text {low }} \leqslant T_{\text {jacket }}(t) \leqslant T_{\text {high }}$ by Lemma 5.3, we obtain now the bounds $T_{l}, T_{h}$ on the temperature $T(t)$. Namely, using (5.1), hypothesis $\left(H_{1}\right)$ and (5.7), we first obtain $T_{l}(t) \leqslant T(t) \leqslant T_{h}(t)$, where

$T_{l}=\left[\left(T_{\text {feed }}-T_{\text {ref }}\right)\left(M_{\max }-M_{0}\right)+T(0)+\underline{\xi} \sigma M_{\max }\right] e^{-\left(M_{\max }-M_{0}+t U A_{0}\right)}+\underline{\xi} e^{-\left(M_{\max }-M_{0}\right)}\left(1-e^{-t U A_{0}}\right)$ 
with $\underline{\xi}=\min \left\{T_{\text {ref }}, T_{\text {low }}\right\}$, and

$$
T_{h}=\left(\bar{\xi} M_{\max }+T(0)\right) \frac{e^{-t P_{0} \sigma M_{\max }}}{U A_{0}}+\frac{A_{\max }}{A_{0}}
$$

with $\bar{\xi}=\max \left\{T_{\text {ref }}, T_{\text {high }}\right\}, P_{0}=\left(C_{\mathrm{H}_{2} \mathrm{O}}^{p}+C_{\alpha}^{p}+C_{\beta}^{p}+C_{\text {cry }}^{p}\right)^{-1} M_{\text {max }}^{-1}$. Here $A_{\max }$ is the maximal surface which corresponds to $V_{\max }$ and $A_{0}$ is the surface which corresponds to $V_{0}$. Now the bounds are $T_{l}=$ $\min _{t \geqslant 0} T_{l}(t)$ and $T_{h}=\max _{t \geqslant 0} T_{h}(t)$. Since all the elements used to compute $T_{h}$ can be computed, we can arrange $T_{h} \leqslant 90^{\circ}$.

COROLlaRY 5.1 From the bounds $T_{l} \leqslant T(t) \leqslant T_{h}$ we obtain bounds

$$
k_{i}(T(t)) \leqslant \kappa \text { for } i \in\{1,2, m\} \text { and } t \geqslant 0
$$

on the mutarotation exchange rates.

Proof. By using the bounds $T_{l} \leqslant T(t) \leqslant T_{h}$ and the expressions of mutarotation $k_{2}(T)=k_{0} \exp \left(-\frac{E_{a}}{R_{g}(T+273.15)}\right)$, $k_{m}(T)=1.64-0.0027 T$ and $k_{1}(T)=k_{2}(T) k_{m}(T)$, we obtain

$$
\begin{gathered}
k_{2}(T) \leqslant k_{0} \exp \left(-\frac{E_{a}}{R_{g}\left(T_{h}+273.15\right)}\right):=\overline{k_{2}} \\
k_{m}(T) \leqslant 1.64-0.0027 T_{l}:=\overline{k_{m}} \\
k_{1}(T) \leqslant \overline{k_{2} k_{m}}:=\overline{k_{1}}
\end{gathered}
$$

Then for $\kappa=\max \left\{\overline{k_{2}}, \overline{k_{m}}, \overline{k_{1}}\right\}$, we deduce

$$
k_{i}(T(t)) \leqslant \kappa \text { for } i \in\{1,2, m\} \text { and } t \geqslant 0 .
$$

Corollary 5.2 From hypotheses $\left(H_{1}\right)$ and $\left(H_{2}\right)$ we obtain a bound $G\left(c_{\alpha}(t), c_{\beta}(t), T(t)\right) \leqslant G_{f}, t \geqslant 0$ on the growth rate.

Proof. By using the hypothesis $\left(H_{1}\right),\left(H_{2}\right)$ and the relations $m_{\alpha}(t)=c_{\alpha}(t) m_{\mathrm{H}_{2} \mathrm{O}}(t)$ and $m_{\beta}(t)=$ $c_{\beta}(t) m_{\mathrm{H}_{2} \mathrm{O}}(t)$, we obtain $m_{\text {cry }}(t) \leqslant M_{\max }, c_{\alpha}(t) \leqslant \frac{M_{\max }}{m_{\mathrm{H}_{2} \mathrm{O}}(0)}:=c_{m}$ and $c_{\beta}(t) \leqslant \frac{M_{\max }}{m_{\mathrm{H}_{2} \mathrm{O}}(0)}:=c_{m}$ for all $t \geqslant$ 0 . Now using the bound $T_{h}$ obtained in lemma 5.3 , we can put $c_{s}:=c_{\alpha, \text { sat,eq }}\left(T_{h}\right)\left(1+k_{m}\left(T_{h}\right) F\left(T_{h}\right)\right)$. Then $G\left(c_{\alpha}, c_{\beta}, T\right) \leqslant G_{f}:=k_{g}\left(c_{m}-c_{s}\right)$.

\subsection{Hypothesis on mass of water using the feed rate}

In this section we discuss a hypothesis which assures that the mass of water does not become too small and stays bounded away from 0 . This has also to be assured either by control of the feed, or via the initial values by assuring that a sufficient quantity of water is present at $t=0$. We start by observing that $\left(H_{3}\right)$ may be written equivalently as

$$
\left(H_{3}\right) \quad m_{\mathrm{H}_{2} \mathrm{O}}(0)>0 \text { and } \theta:=1-(R-1)\left(c_{\alpha, 0}+c_{\beta, 0}\right)>0,
$$

where $R$ is introduced in (2.9). Now we have the following 
Lemma 5.4 Suppose hypothesis $\left(H_{3}\right)$ is satisfied. Then the mass of water in the slurry satisfies $m_{\mathrm{H}_{2} \mathrm{O}}(t) \geqslant \theta m_{\mathrm{H}_{2} \mathrm{O}}(0)>0$ for all $t \geqslant 0$.

Proof. By adding (2.12) and (2.14), we obtain

$$
m_{\text {cry }}^{\prime}(t)=-R\left[m_{\alpha}^{\prime}(t)+m_{\beta}^{\prime}(t)\right]+R\left(c_{\alpha, 0}+c_{\beta, 0}\right) q_{\mathrm{H}_{2} \mathrm{O}}(t) .
$$

By substituting (5.14) in (2.11), we obtain

$$
m_{\mathrm{H}_{2} \mathrm{O}}^{\prime}(t)=(R-1)\left[m_{\alpha}^{\prime}(t)+m_{\beta}^{\prime}(t)\right]+\theta q_{\mathrm{H}_{2} \mathrm{O}}(t)
$$

where $\theta=1-(R-1)\left(c_{\alpha, 0}+c_{\beta, 0}\right)$. By integrating (5.15), we obtain

$$
\begin{aligned}
m_{\mathrm{H}_{2} \mathrm{O}}(t) & =m_{\mathrm{H}_{2} \mathrm{O}}(0)-(R-1)\left(m_{\alpha}(0)+m_{\beta}(0)\right)+(R-1)\left(m_{\alpha}(t)+m_{\beta}(t)\right)+\theta \int_{0}^{t} q_{\mathrm{H}_{2} \mathrm{O}}(\tau) d \tau \\
& =\theta m_{\mathrm{H}_{2} \mathrm{O}}(0)+\theta \int_{0}^{t} q_{\mathrm{H}_{2} \mathrm{O}}(\tau) d \tau+(R-1)\left(m_{\alpha}(t)+m_{\beta}(t)\right)
\end{aligned}
$$

In the worst case all lactose molecules in the liquid phase may crystallize, so that

$$
m_{\mathrm{H}_{2} \mathrm{O}}(t) \geqslant \theta \int_{0}^{t} q_{\mathrm{H}_{2} \mathrm{O}}(\tau) d \tau+\theta m_{\mathrm{H}_{2} \mathrm{O}}(0) \geqslant \theta m_{\mathrm{H}_{2} \mathrm{O}}(0)>0 .
$$

REMARK 5.1 Hypothesis $\left(H_{3}\right)$ assures that the water initially present in the crystallizer cannot be completely consumed through crystallization in finite time even in batch mode, where $q=0$. This corresponds to an upper bound on the fraction of lactose:

$$
m_{\text {lactose }} \leqslant\left(\frac{M_{\text {cry }}}{M_{\alpha}}-1\right)^{-1} m_{\mathrm{H}_{2} \mathrm{O}}=19.04 m_{\mathrm{H}_{2} \mathrm{O}}
$$

which using (2.25) leads to the temperature-dependent bound

$$
m_{\alpha} \leqslant \frac{M_{\alpha}}{\left(M_{\text {cry }}-M_{\alpha}\right)\left(1+k_{m}(T)\right)} m_{\mathrm{H}_{2} \mathrm{O}}
$$

at the equilibrium of mutarotation. This should be compared to the lower bound given by the supersaturation constraint, which at the equilibrium of mutarotation according to section 2.7 gives

$$
m_{\alpha} \geqslant \frac{\theta_{1} \exp \left(\theta_{2} T\right)}{100\left(1+k_{m}(T)\right)} m_{\mathrm{H}_{2} \mathrm{O}}
$$

In (5.19) the solubility concentration ranges from $c_{\alpha}=m_{\alpha} / m_{\mathrm{H}_{2} \mathrm{O}}=0.0478$ at $5^{\circ} \mathrm{C}$ to $c_{\alpha}=0.5678$ at $90^{\circ} \mathrm{C}$, while the upper bound (5.18) ranges from $c_{\alpha}=7.24$ at $5^{\circ} \mathrm{C}$ to $c_{\alpha}=7.9433$ at $90^{\circ} \mathrm{C}$. Since crystallizers are operated in the range between solubility and supersolubility, which in the case of lactose is roughly twice the solubility concentration, cf. (Yee et al., 2011, Fig. 1), concentrations $c_{\alpha}>1$ are highly unrealistic, so that the bound (5.18) is in no way restrictive. 


\section{Global existence and uniqueness of solutions}

In this section we will assemble the results from the previous sections and prove global existence and uniqueness of solutions of the crystallizer model. We use the method of characteristics with a fixed-point argument for an operator $\mathscr{Q}$ which we now define.

\subsection{Setting up the operator}

For the function $w$ defined via (4.2) we introduce the Banach space

$$
\mathbf{E}=C\left(\mathbb{R}^{+} \times\left[0, t_{f}\right]\right) \cap \mathscr{L}_{u}^{1}\left(\mathbb{R}^{+} \times\left[0, t_{f}\right], h(L) d L\right),
$$

where we set $h(L)=\max \left\{1, L^{3}\right\}$. We introduce the norm on $\mathbf{E}$ as

$$
\|w\|=\|w\|_{\infty}+\sup _{0 \leqslant t \leqslant t_{f}} \int_{0}^{\infty}|w(L, t)| h(L) d L .
$$

where the fact that in the second term a supremum over $t \in\left[0, t_{f}\right]$ is formed is indicated by the index $u$, for uniform, in $\mathscr{L}_{u}^{1}$. Let us introduce the moments of the CSD as

$$
\mu_{i}(t)=\int_{0}^{\infty} V(t) n(L, t) L^{i} d L, i=0,1, \ldots
$$

so that $m_{\text {cry }}=\rho k_{v} \mu_{3}$. The initial conditions are then

$$
\mu_{i, 0}=\int_{0}^{\infty} V(0) n_{0}(L) L^{i} d L, i=0,1, \ldots
$$

We consider $\mathbf{x}=\left(m_{\alpha}, m_{\beta}, m_{\mathrm{H}_{2} \mathrm{O}}, T, m_{\text {cry }}, \mu_{2}, \mu_{1}, \mu_{0}, w\right)$ an element of the space

$$
\mathbf{F}=C\left[0, t_{f}\right]^{8} \times \mathbf{E},
$$

where each copy of $C\left[0, t_{f}\right]$ is equipped with the supremum norm, so that the norm on $\mathbf{F}$ is

$$
|\mathbf{x}|=\left\|m_{\alpha}\right\|_{\infty}+\left\|m_{\beta}\right\|_{\infty}+\left\|m_{\mathrm{H}_{2} \mathrm{O}}\right\|_{\infty}+\|T\|_{\infty}+\left\|m_{\text {cry }}\right\|_{\infty}+\left\|\mu_{2}\right\|_{\infty}+\left\|\mu_{1}\right\|_{\infty}+\left\|\mu_{0}\right\|_{\infty}+\|w\| .
$$

We proceed to define the action of the operator $\mathscr{Q}$ on element $\mathbf{x} \in \mathbf{F}$, writing

$$
\mathscr{Q} \mathbf{x}=\widetilde{\mathbf{x}}=\left(\widetilde{m}_{\alpha}, \widetilde{m}_{\beta}, \widetilde{m}_{\mathrm{H}_{2} \mathrm{O}}, \widetilde{m}_{\text {cry }}, \widetilde{T}, \widetilde{\mu}_{2}, \widetilde{\mu}_{1}, \widetilde{\mu}_{0}, \widetilde{w}\right) .
$$

The initial values at $t=0$ are

$$
\mathbf{x}_{0}=\left(m_{\alpha, 0}, m_{\beta, 0}, m_{\mathrm{H}_{2} \mathrm{O}, 0}, m_{\mathrm{cry}, 0}, T_{0}, \mu_{2,0}, \mu_{1,0}, \mu_{0,0}, w_{0}\right),
$$

all specified through table (5).

We define $\widetilde{m}_{\alpha}$ as the left hand side of (4.8), so that it is a function of the old elements $T, m_{\text {cry }}$ in $\mathbf{x}$ and the initial values $\mathbf{x}(0)=\mathbf{x}_{0}$. Similarly, we define $\widetilde{m}_{\beta}$ as the left hand side of formula (4.9). Note that we need the derivative $m_{\text {cry }}^{\prime}$ to define these elements, and that can be expressed by the second 


\begin{tabular}{||c|c||}
\hline \hline initial value & expression \\
\hline \hline$m_{\alpha, 0}$ & $(2.23)$ \\
\hline$m_{\beta, 0}$ & $(2.24)$ \\
\hline$m_{\mathrm{H}_{2} \mathrm{O}, 0}$ & $(2.21)$ \\
\hline$T_{0}$ & $(2.26)$ \\
\hline$m_{\text {cry }, 0}$ & $(2.8)$ \\
\hline$\mu_{i, 0}$ & $(6.2)$ \\
\hline$w_{0}$ & $(4.5)$ \\
\hline \hline
\end{tabular}

Table 5. Expression of initial values

moment $\mu_{2}$, which is part of $\mathbf{x}$. In fact by substituting the population balance (4.1) in the expression $m_{\text {cry }}^{\prime}(t)=\rho k_{v} \int_{0}^{\infty} \frac{\partial(V(t) n(L, t))}{\partial t} L^{3} d L$, we obtain

$$
\begin{aligned}
m_{\mathrm{cry}}^{\prime}(t) & =-\rho k_{v} \int_{0}^{\infty}\left[G\left(c_{\alpha}(t), c_{\beta}(t), T(t)\right) \frac{\partial(V(t) n(L, t))}{\partial L}+a(L) V(t) n(L, t)-w(L, t)\right] L^{3} d L \\
& =3 \rho k_{v} G\left(c_{\alpha}(t), c_{\beta}(t), T(t)\right) \int_{0}^{\infty} V(t) n(L, t) L^{2} d L-\rho k_{v} \int_{0}^{\infty} a(L) V(t) n(L, t) L^{3} d L \\
& +\rho k_{v} \int_{0}^{\infty} w(L, t) L^{3} d L \\
& =3 \rho k_{v} G\left(c_{\alpha}(t), c_{\beta}(t), T(t)\right) \mu_{2}(t)-\rho k_{v} \int_{0}^{\infty} a(L) V(t) n(L, t) L^{3} d L \\
& +\rho k_{v} \int_{0}^{\infty} w(L, t) L^{3} d L .
\end{aligned}
$$

The third step in the definition of $\mathscr{Q}$ is to define $\widetilde{m}_{\mathrm{H}_{2} \mathrm{O}}$ as the left hand side of formula (4.10). The left hand side of (4.11) defines $\widetilde{T}$, using the elements of $\mathbf{x}$ and $\mathbf{x}_{0}$ on the right. Note that due to the prior estimates we may consider $T_{\text {jacket }}$ as an input.

In order to define the elements $\widetilde{w}$ and $\widetilde{m}_{\text {cry }}$, we first have to introduce the characteristics $\phi_{t, L}$ via formula (4.13), using the old elements $\mathbf{x}$ on the right. Then we define the functions $N_{t, L}$ via formula (4.16). We are now ready to define $\widetilde{m}_{\text {cry }}$ as

$$
\begin{aligned}
\tilde{m}_{\mathrm{cry}}(t)= & \rho k_{v} \int_{0}^{\infty} V(t) n(L, t) L^{3} d L \\
= & \rho k_{v} \int_{0}^{z(t)}\left(\frac{V(\tau) B\left(c_{\alpha}(\tau), c_{\beta}(\tau), T(\tau)\right)}{G\left(c_{\alpha}(\tau), c_{\beta}(\tau), T(\tau)\right)}+\int_{\tau}^{t} w\left(\phi_{\tau, 0}(s), s\right) \exp \left\{\int_{\tau}^{s} a\left(\phi_{\tau, 0}(\sigma)\right) d \sigma\right\} d s\right) \\
& \times \exp \left(-\int_{\tau}^{t} a\left(\phi_{\tau, 0}(s)\right) d s\right) L^{3} d L \\
+ & \rho k_{v} \int_{z(t)}^{\infty}\left(V(0) n_{0}\left(\phi_{t, L}(0)\right)+\int_{0}^{t} w\left(\phi_{t, L}(s), s\right) \exp \left\{\int_{0}^{s} a\left(\phi_{t, L}(\sigma)\right) d \sigma\right\} d s\right) \\
& \times \exp \left(-\int_{0}^{t} a\left(\phi_{t, L}(s)\right) d s\right) L^{3} d L .
\end{aligned}
$$


In the first integral $\int_{0}^{z(t)}$ we use the change of variables $L \rightarrow \tau=\tau(t, L)$. Then

$$
[0, z(t)] \ni L \mapsto \tau(t, L) \in[0, t], \quad d L=G\left(c_{\alpha}(t), c_{\beta}(t), T(t)\right) d \tau
$$

In the second integral $\int_{z(t)}^{\infty}$ we use the change of variables $L \rightarrow \xi(t, L):=\phi_{t, L}(0)$. Then

$$
[z(t), \infty) \ni L \mapsto \xi \in[0, \infty), \quad d L=d \xi
$$

The inverse relation is $L=\xi+\int_{0}^{t} G\left(c_{\alpha}(\sigma), c_{\beta}(\sigma), T(\sigma)\right) d \sigma=\xi+z(t)$. From (6.4) we therefore obtain

$$
\begin{array}{r}
\tilde{m}_{\mathrm{cry}}(t)=\rho k_{v} \int_{0}^{t}\left(V(\tau) B\left(c_{\alpha}(\tau), c_{\beta}(\tau), T(\tau)\right)+\int_{\tau}^{t} w\left(\phi_{\tau, 0}(s), s\right) \exp \left\{\int_{\tau}^{s} a\left(\phi_{\tau, 0}(\sigma)\right) d \sigma\right\} d s\right) \\
\times \exp \left(-\int_{\tau}^{t} a\left(\phi_{\tau, 0}(s)\right) d s\right) L(\tau)^{3} d \tau \\
+\rho k_{v} \int_{0}^{\infty}\left(V(0) n_{0}(\xi)+\int_{0}^{t} w\left(\phi_{0, \xi}(s), s\right) \exp \left\{\int_{0}^{s} a\left(\phi_{0, \xi}(\sigma)\right) d \sigma\right\} d s\right) \\
\times \exp \left(-\int_{0}^{t} a\left(\phi_{0, \xi}(s)\right) d s\right) L(\xi)^{3} d \xi
\end{array}
$$

where $L(\tau)=\int_{\tau}^{t} G\left(c_{\alpha}(\sigma), c_{\beta}(\sigma), T(\sigma)\right) d \sigma$ and $L(\xi)=\xi+\int_{0}^{t} G\left(c_{\alpha}(\sigma), c_{\beta}(\sigma), T(\sigma)\right) d \sigma$, and where we use $\phi_{t, L}(s)=\phi_{0, \xi}(s)$ in the second integral. For fixed $t$ the functions $L \mapsto \tau(t, L)$ and $\tau \mapsto L(\tau)$ are inverses of each other, and similarly, $L \leftrightarrow \xi$ are in one-to-one correspondence via the formula $L=$ $\xi-\int_{0}^{t} G\left(c_{\alpha}(\sigma), c_{\beta}(\sigma), T(\sigma)\right) d \sigma$.

Similarly, continuing to define the operator $\mathscr{Q}$, we define the moments $\widetilde{\mu}_{i}, i=0,1,2$ within $\widetilde{\mathbf{x}}$ via

$$
\widetilde{\mu}_{i}(t)=\int_{0}^{\infty} V(t) n(L, t) L^{i} d L
$$

where we express the right hand side via characteristics and the elements of $\mathbf{x}$ in much the same way as done for $\tilde{m}_{\text {cry. }}$.

We also need to get back to the function $\widetilde{w}(L, t)$. We introduce

$$
\beta\left(L, L^{\prime}\right)= \begin{cases}a(L) b\left(L, L^{\prime}\right), & \text { if } L \geqslant L^{\prime} \\ 0, & \text { else }\end{cases}
$$

then we can write

$$
\widetilde{w}\left(L^{\prime}, t\right)=\int_{L^{\prime}}^{\infty} a(L) b\left(L, L^{\prime}\right) V(t) n(L, t) d L=\int_{0}^{\infty} \beta\left(L, L^{\prime}\right) V(t) n(L, t) d L
$$

which is essentially like the moment integral (6.5), the function $L \mapsto L^{i}$ being replaced by $\beta\left(L, L^{\prime}\right)$.

Applying the same technique as in the case of (6.5), we obtain 


$$
\begin{array}{r}
\widetilde{w}\left(L^{\prime}, t\right)=\int_{0}^{t}\left(V(\tau) B\left(c_{\alpha}(\tau), c_{\beta}(\tau), T(\tau)\right)+\int_{\tau}^{t} w\left(\phi_{\tau, 0}(s), s\right) \exp \left\{\int_{\tau}^{s} a\left(\phi_{\tau, 0}(\sigma)\right) d \sigma\right\} d s\right) \\
\times \exp \left(-\int_{\tau}^{t} a\left(\phi_{\tau, 0}(s)\right) d s\right) \beta\left(L(\tau), L^{\prime}\right) d \tau \\
+\int_{0}^{\infty}\left(V(0) n_{0}(\xi)+\int_{0}^{t} w\left(\phi_{t, L}(s), s\right) \exp \left\{\int_{0}^{s} a\left(\phi_{t, L}(\sigma)\right) d \sigma\right\} d s\right) \\
\times \exp \left(-\int_{0}^{t} a\left(\phi_{t, L}(s)\right) d s\right) \beta\left(L(\xi), L^{\prime}\right) d \xi
\end{array}
$$

which expresses $\widetilde{w}$ in terms of $w$ and the characteristics, hence by elements of $\mathbf{x}$. Here we use $w \in \mathbf{E}$, and it is routine to check that $\widetilde{w} \in \mathbf{E}$, so that $\widetilde{\mathbf{x}} \in \mathbf{F}$. This completes the definition of $\mathscr{Q}$.

We will also need the following hypotheses on the breakage terms $a$ and $b$ :

$$
\begin{gathered}
\quad\|a\|_{\infty}:=\max _{0 \leqslant L<\infty} a(L)<+\infty, \quad\|a\|_{L}=\sup _{0 \leqslant L<L^{\prime}}\left|\frac{a(L)-a\left(L^{\prime}\right)}{L-L^{\prime}}\right|<\infty, \\
\left(H_{5}\right) \quad\|b\|_{\infty}:=\max _{0 \leqslant L \leqslant L^{\prime}} b\left(L^{\prime}, L\right)<+\infty, \quad\|b\|_{L}:=\sup _{L \geqslant 0} \sup _{L \leqslant L^{\prime}<L^{\prime \prime}}\left|\frac{b\left(L, L^{\prime}\right)-b\left(L, L^{\prime \prime}\right)}{L^{\prime}-L^{\prime \prime}}\right|<\infty,
\end{gathered}
$$

and

$$
\text { ( } \left.H_{6}\right) \quad \int_{0}^{L^{\prime}} \beta\left(L^{\prime}, L\right) L^{3} d L \leqslant c L^{\prime 3} \quad \text { for some } c>0 .
$$

Note that $\left(H_{6}\right)$ is in particular true if conservation of mass in breakage (2.6) is satisfied.

\subsection{Setting up the space}

We now have to define a closed subset $\mathbf{X}$ of $\mathbf{F}$ on which the operator $\mathscr{Q}$ acts as a contraction with respect to the metric induced by the norm of $\mathbf{F}$. In other words, we need to assure $\mathscr{Q}(\mathbf{X}) \subset \mathbf{X}$ and

$$
\left|\mathscr{Q} \mathbf{x}^{(1)}-\mathscr{Q} \mathbf{x}^{(2)}\right| \leqslant \gamma\left|\mathbf{x}^{(1)}-\mathbf{x}^{(2)}\right|
$$

for a constant $0<\gamma<1$ and all $\mathbf{x}^{(1)}, \mathbf{x}^{(2)} \in \mathbf{X}$. This will be achieved by choosing $t_{f}$ small enough, as usual, but in order to prove global existence, we will have to make a careful quantification of $\gamma$ in terms of $t_{f}$ and the initial values $\mathbf{x}_{0}$, because we wish to iterate the local existence argument.

We distinguish between globally bounded states and those for which no prior bound can be put forward. Due to our hypotheses $\left(H_{1}\right),\left(H_{2}\right),\left(H_{3}\right)$ the masses $m_{\alpha}, m_{\beta}, m_{\text {cry }}, m_{\mathrm{H}_{2} \mathrm{O}}$ and the temperature $T$ are globally bounded, the bounds being given by formulas (5.8). We write

$$
\mathbf{y}=\left(m_{\alpha}, m_{\beta}, m_{\mathrm{H}_{2} \mathrm{O}}, m_{\text {cry }}, T\right)
$$

for the globally bounded states. On the other hand, it is not clear whether the moments $\mu_{2}, \mu_{1}, \mu_{0}$ nor $w$ are globally bounded, and whether such a bound can be obtained from the physical constraints. This is due to particle breakage, which may lead to an exceedingly large number of small particles, or fines. We write

$$
\mathbf{z}=\left(\mu_{0}, \mu_{1}, \mu_{2}\right) \text { and } w \in \mathbf{E}
$$


for the unbounded state. Altogether

$$
\mathbf{x}=(\mathbf{y}, \mathbf{z}, w) \in \mathbf{F} .
$$

During the following we therefore assume that the initial data for the bounded states $\mathbf{y}_{0}=\left(m_{\text {cry }, 0}, m_{\mathrm{H}_{2} \mathrm{O}, 0}, m_{\alpha, 0}, m_{\beta, 0}, T_{0}\right)$ respect these global bounds, that is

$$
m_{\alpha, 0}+m_{\beta, 0}+m_{\text {cry }, 0}+m_{\mathrm{H}_{2} \mathrm{O}, 0}<M_{\max }
$$

$m_{\mathrm{H}_{2} \mathrm{O}, 0}>0, \theta:=1-(R-1)\left(c_{\alpha, 0}+c_{\beta, 0}\right)>0$ and for the temperature

$$
T_{l}<T(0)<T_{h}
$$

The hypotheses $\left(H_{1}\right),\left(H_{2}\right),\left(H_{3}\right)$ on the controls $q_{\mathrm{H}_{2} \mathrm{O}}$ and $T_{\mathrm{sp}}$ will then assure that on every interval of existence of a solution $\mathbf{x}(t)$, the bounded states $\mathbf{y}(t)$ satisfy the same global bounds. We split the initial conditions into $\mathbf{x}_{0}=\left(\mathbf{y}_{0}, \mathbf{z}_{0}, w_{0}\right)$, where $\mathbf{y}_{0}$ is the bounded part, $\mathbf{z}_{0}, w_{0}$ that part which does not have a prior bound. The state $\mathbf{x}(t)$ is split accordingly as $\mathbf{x}(t)=(\mathbf{y}(t), \mathbf{z}(t), w(t))$. Now define the moments of $w(L, t)$ as

$$
\mu_{w, i}(t)=\int_{0}^{\infty} w(L, t) L^{i} d L
$$

and fix $K>\left|\mathbf{z}_{0}\right|+\left|\mu_{w, 0}(0)\right|+\left|\mu_{w, 1}(0)\right|+\left|\mu_{w, 2}(0)\right|+\left|\mu_{w, 3}(0)\right|$. Then we define the space $\mathbf{X}$ as

$$
\mathbf{X}=\left\{\mathbf{x} \in \mathbf{F}: \mathbf{x}(0)=\mathbf{x}_{0}, \mathbf{x}=(\mathbf{y}, \mathbf{z}, w),|\mathbf{z}(t)|+\sum_{i=0}^{3}\left|\mu_{w, i}(t)\right| \leqslant K \text { for all } t \in\left[0, t_{f}\right]\right\}
$$

LEMMA 6.1 There exists a constant $c>0$ depending only on the global volume bound $V_{\max }$ such that for every $\mathbf{y}_{0}$ satisfying (6.7), every $\mathbf{z}_{0}, w_{0}$, and every $K>\left|\mathbf{z}_{0}\right|+\sum_{i=0}^{3}\left|\mu_{w, i}(0)\right|$ the following is true: Suppose $t_{f}>0$ satisfies

$$
0<t_{f}<\left(K-\left|\mathbf{z}_{0}\right|-\sum_{i=0}^{3}\left|\mu_{w, i}(0)\right|\right) / c
$$

Then $\mathscr{Q}(\mathbf{X}) \subset \mathbf{X}$.

Proof. Integrating over an interval $\left[0, t_{f}\right]$ leads to estimates of the form

$$
\widetilde{\mathbf{z}}(t)=\mathbf{z}_{0}+\int_{0}^{t} f(\mathbf{y}(\tau), \mathbf{z}(\tau), w(\tau)) d \tau \leqslant\left|\mathbf{z}_{0}\right|+(c+K) t_{f}, \text { for all } 0 \leqslant t \leqslant t_{f}
$$

where a global bound $c$ for $\mathbf{y}(t)$ is used on $\left[0, t_{f}\right]$, while the bounds $|\mathbf{z}(t)| \leqslant K,\left|\mu_{w, i}(t)\right| \leqslant K$ are used for the states $\mathbf{z}, w$. Then in order to assure $|\widetilde{\mathbf{z}}(t)| \leqslant K$, we have but to force the condition

$$
\left|\mathbf{z}_{0}\right|+c(1+K) t_{f} \leqslant K
$$

which gives $t_{f} \leqslant \frac{K-\left|\mathbf{z}_{0}\right|}{c(1+K)} \leqslant \frac{K-\left|\mathbf{z}_{0}\right|}{c}$. A similar argument applies to the moments $\mu_{w, i}$ of $w$, and combining the two gives (6.8). For the state $w$, hypothese $\left(H_{6}\right)$ is used to prove $\left|\mu_{w, i}(t)\right| \leqslant K$. 


\subsection{Proving $\gamma \in(0,1)$}

For the globally bounded states gathered in $\mathbf{y}$ we obtain an estimate of the form

$$
\left\|\widetilde{\mathbf{y}}^{(1)}-\widetilde{\mathbf{y}}^{(2)}\right\| \leqslant c_{1}\left(1+\left|\mathbf{z}_{0}\right|+K\right) t_{f}\left|\mathbf{x}^{(1)}-\mathbf{x}^{(2)}\right|
$$

for a global constant $c_{1}$ depending only on $V_{\max }$. For the state $\mathbf{z}=\left(\mu_{0}, \mu_{1}, \mu_{2}\right)$ on the other hand we obtain an estimation of the form

$$
\left\|\widetilde{\mathbf{z}}^{(1)}-\widetilde{\mathbf{z}}^{(2)}\right\| \leqslant c_{2}\left(1+\left|\mathbf{z}_{0}\right|+\sum_{i=0}^{3}\left|\mu_{w, i}(0)\right|+K\right) t_{f}\left|\mathbf{x}^{(1)}-\mathbf{x}^{(2)}\right|,
$$

where $c_{2}$ is another global constant. The Lipschitz constant now depends on the intial contition $\mathbf{z}_{0}$, $\mu_{w, i}(0)$, for which no global bound is available. A similar estimate

$$
\left\|\widetilde{w}^{(1)}-\widetilde{w}^{(2)}\right\| \leqslant c_{3}\left(1+\left\|\mathbf{z}_{0}\right\|+\sum_{i=0}^{3}\left|\mu_{w, i}(0)\right|+K\right) t_{f}\left|\mathbf{x}^{(1)}-\mathbf{x}^{(2)}\right|
$$

is obtained for the terms involving $w$. Altogether, we have

Lemma 6.2 There exists a constant $c$ depending only on $V_{\max }$ such that for every initial condition $\mathbf{y}_{0}$ satisfying (6.7), every initial $\mathbf{z}_{0}, w_{0}$, and every $K$ with $\left\|\mathbf{z}_{0}\right\|+\sum_{i=0}^{3}\left|\mu_{w, i}(0)\right|<K$, the operator $\mathscr{Q}$ satisfies the following Lipschitz estimate on $\mathbf{X}$ :

$$
\left|\mathscr{Q} \mathbf{x}^{(1)}-\mathscr{Q} \mathbf{x}^{(2)}\right| \leqslant c\left(1+\left|\mathbf{z}_{0}\right|+\sum_{i=0}^{3}\left|\mu_{w, i}(0)\right|+K\right) t_{f}\left|\mathbf{x}^{(1)}-\mathbf{x}^{(2)}\right| .
$$

Condition (6.9) in tandem with (6.8) allows us now to apply the Banach contraction theorem to the operator $\mathscr{Q}$. Using this, we can prove the theorem 3.1.

\subsection{Proof of Theorem 3.1}

In this section, we present the proof of the theorem 3.1 of existence and uniqueness of solution.

Proof. 1) Suppose we choose $K>\left|\mathbf{z}_{0}\right|+\sum_{i=0}^{3}\left|\mu_{w, i}(0)\right|$, then

$$
t_{f}=\min \left\{\frac{K-\left|\mathbf{z}_{0}\right|-\sum_{i=0}^{3}\left|\mu_{w, i}(0)\right|}{c+K}, \frac{1}{2 c\left(1+\left|\mathbf{z}_{0}\right|+\sum_{i=0}^{3}\left|\mu_{w, i}(0)\right|+K\right)}\right\}
$$

assures that $\mathscr{Q}$ is a self-map and a contraction on $\mathbf{X}$, so that a unique solution with the initial condition $\mathbf{x}_{0}$ exists on $\left[0, t_{f}\right]$.

2) We will now have to iterate the process, and for that we shall change our notation. We write $\mathbf{w}(t)=|\mathbf{z}(t)|+\sum_{i=0}^{3}\left|\mu_{w, i}(t)\right|$. We started the method at $t_{0}=0$. Putting $\mathbf{w}_{0}=\mathbf{w}(0)$, we chose $K=$ $\mathbf{w}_{0}+1>\mathbf{w}(0)$ in part 1$)$ above, so that condition (6.10) re-written at $t_{f}=t_{1}$ becomes

$$
t_{1}=\min \left\{\frac{1}{c+\mathbf{w}_{0}+1}, \frac{1}{4 c\left(1+\mathbf{w}_{0}\right)}\right\}
$$

This gave a unique solution on $\left[0, t_{f}\right]=\left[t_{0}, t_{1}\right]$. 
3) Since by construction of $\mathbf{X}$ on $\left[t_{0}, t_{1}\right]=\left[0, t_{f}\right]$ we have $\mathbf{w}(t) \leqslant K$ for every $t \in\left[t_{0}, t_{1}\right]$, we get $\mathbf{w}_{1} \leqslant K=\mathbf{w}_{0}+1$. In addition, the initial condition of the bounded states $\mathbf{y}$ respects (6.7) and therefore the global bound related to $V_{\max }$, so that we will be able to continue to use the same global constant $c$ in the next iteration. We now use $\mathbf{x}\left(t_{1}\right)$ as the new initial condition at the new initial time $t_{1}$ and repeat the same argument to the right of $t_{1}$. That requires choosing a new constant $K>\left|\mathbf{z}\left(t_{1}\right)\right|+\sum_{i=0}^{3}\left|\mu_{w, i}\left(t_{1}\right)\right|=$ $\mathbf{w}\left(t_{1}\right)=\mathbf{w}_{1}$. We choose again $K=\mathbf{w}_{1}+1$. Then the final time corresponding to $t_{f}$, which is now called $t_{2}-t_{1}$, has to satisfy (6.10), which reads

$$
t_{2}-t_{1}=\min \left\{\frac{1}{c+\mathbf{w}_{1}+1}, \frac{1}{2 c\left(1+\mathbf{w}_{1}+K\right)}\right\} \geqslant \min \left\{\frac{1}{c+\mathbf{w}_{0}+2}, \frac{1}{4 c\left(2+\mathbf{w}_{0}\right)}\right\} .
$$

By recursion we find that

$$
t_{n}-t_{n-1} \geqslant \min \left\{\frac{1}{c+\mathbf{w}_{0}+n}, \frac{1}{4 c\left(n+\mathbf{w}_{0}\right)}\right\}
$$

so that for some constant $c^{\prime}$ depending only on $V_{\max }$ and $\mathbf{w}_{0}=\left|\mathbf{z}_{0}\right|+\sum_{i=0}^{3}\left|\mu_{w, i}(0)\right|$,

$$
t_{N}=\sum_{n=1}^{N} t_{n}-t_{n-1} \geqslant c^{\prime} \sum_{n=1}^{N} \frac{1}{n} \rightarrow \infty(N \rightarrow \infty)
$$

Since the solution can be continued from 0 to any $t_{N}$, this proves global existence and uniqueness.

REMARK 6.1 An interesting consequence of the proof is that no global bound for the moments $\mu_{0}, \mu_{1}, \mu_{2}$ is found from the physically meaningful assumptions of section 5. In particular, it cannot be excluded that despite the bounds on volume and mass a large number of exceedingly small crystals, called fines, may hinder the sustainable growth of larger solids. This phenomenon is really observed in practice. In continuous crystallizers it is therefore mandatory to employ a third control mechanism, the recycling of fines, in order to limit their impact on growth. In Apkarian et al. (2011) we have studied feedback control with recycling of fines.

\section{Conclusion}

We have presented and discussed a model of the process of crystallization of $\alpha$-lactose monohydrate. The model was validated mathematically by proving existence and uniqueness of global solutions under realistic conditions assuring bounds on mass, volume and temperature of slurry. We observed that no global bounds on crystal surface, length and number can be obtained, but the result shows that none of the states can grow infinitely in finite time.

\section{REFERENCES}

Apkarian, P. \& Hosseini-Ravanbod, L. \& Noll, D. (2011) Time-domain constrained structured $H_{\infty}$ synthesis. International Journal of Robust and Nonlinear Control. 21, 197-217.

Bronlund, J. (1997) The modelling of caking in bulk lactose. PhD Thesis, Massey University.

Butler, B. (1998) Modelling industrial of lactose cristallization. PhD Thesis, University of Queensland.

CALsina, A. \& SALDAÑA, J. (1995) A model of physiologically structured population dynamics with a nonlinear individual growth rate. Journal of Mathematical Biology. 33, 335-364.

Cushing, J. M. (1989) A competition model for size-structured species. SIAM Journal Applied Mathematical. 49, 838-858. 
Dincer, T. D. (2000) Mechanisms of lactose cristallization. PhD Thesis, School of applied chemistry, Curtin university of technology, volume 197.

Evans, L. C. (2001) Partial Differential Equations, second edition. American Mathematical Society, Providence Rhode, Island.

Gernigon, G. (2012) Modélisation de la cinétique de cristallisation du lactose en solution-modèles-application à la transformation des lactosérums de mozerella. $\mathrm{PhD}$ Thesis, Institut supérieur des sciences agronomiques, agro-alimentaires, horticoles et du paysage de Rennes.

Gurtin, M. E. \& MACCAMY, R. C. (1974) Non-linear age-dependent population dynamics. Journal of food science. 54, 281-300.

Hede, P. D. (2006) Modelling Batch Systems Using Population Balances. Bookboon. 58, ISBN : 978-87-7681180-8.

Hounslow, M. J. \& Pearson, J. M. K. \& Instone, T. (2001) Tracer Studies of High-Shear Granulation: II. Population Balance Modeling . AIChE Journal. 47, 1984-1999.

JONES, A. G. (2002) Crystallization process systems. Butterworth-Heinemann.

Kostoglou, M. \& Karabelas, A. J. (2002) An assessment of low-order methods for solving the breakage equation. Powder Technology. 127, 116-127.

MARChisio, D. L, DENNis, V. R. \& Fox, R. O. (2003) Quadrature method of moments for aggregation-breakage processes. Journal of Colloid Interface Science. 258, 322-334.

MCLEOD, J. (2007) Nucleation and growth of Alpha lactose Monohydrate. PhD Thesis, Massey University.

McSweeney, P. L. H. \& Fox, P. F. (2009) Advanced Dairy Chemistry Volume 3: Lactose, Water, Salts and Minor Constituents, Third Edition. BUniversity College, Cork, Ireland.

Mersmann, A. (2001) Crystallization Technology Handbook. Marcel Dekker, New York.

Mimouni, A. (2007) Cristallisation du Lactose et apaississement dans les Lactosérums concentrés. PhD Thesis, Ecole Nationale Supérieure Agronomique de Rennes.

Mimouni, A. \& Schuck, P. \& Bouhallab, S. (2009) Isothermal batch crystallisation of alpha-lactose: A kinetic model combining mutarotation, nucleation and growth steps. International Dairy Journal.

Mullin, J.W. \& Nyvlt, J. (1971) Programmed cooling of batch crystallizers. Chemical Engineering Science, 26, 369-377.

Ramkrishna, D. (2000) Population Balances Theory and Applications to Particulate Systems in Engineering. Purdue University School of Chemical Engineering West Lafayette, Indiana, ACADEMIC PRESS, 365.

Reynolds, G.K. \& Fu, J.S. \& Cheong, Y.S. \& Hounslow, M.J.\& SAlman, A.D. (2005) Breakage in granulation: Areview. Chemical Engineering Science. 60, 3969-3992.

SHI, Y. \& LiAnG, B. \& HARTEL, R.W. (1990) Isothermal crystallization of alpha-lactose monohydrate in a continuous cooling crystallizer. Journal of Food science. $\mathbf{5 5}$.

Sмith, H. L. (1994) Existence and uniqueness of global solutions for a size-structured model of an insect population with variable instal duration. Rocky Mountain Journal of Mathematics. 24, 311-334.

TAVAre, N. N. (1995) Industrial cystallization. Process simulation, analysis and design. New York and London.

Thurlby, J. A. \& Sitnal, O. (1976) Lactose crystallization: Investigation of some process alternatives. Journal offood science. 41, 43-47.

Yee Wong, S. \& Bund, R. K. \& Connelly, R. K. \& Hartel, R.W. (2011) Determination of the dynamic metastable limit for $\alpha$-lactose monohydrate crystallization. International Dairy Journal. 21, 839-847.

ZIFF, R. M. \& MCGRADY, E. D. (1985) The kinetics of cluster fragmentation and depolymerisation. Journal of Physics A: Mathematical and General. 18, 3027-3037.

ZIFF, R. M. (1991) New solution to the fragmentation equation. Journal of Physics A: Mathematical and General. 24, 2821-2828. 